\title{
Perú, 2002-2012: crecimiento, cambio estructural y formalización
}

\author{
Juan Chacaltana
}

RESUMEN

Cambiando drásticamente de tendencia, se ha observado un proceso de formalización laboral en el Perú, en un contexto de crecimiento económico, durante el cual también se impulsó una reforma laboral que creó un régimen especial para micro y pequeñas empresas - lo que redujo los costos laborales - y se introdujeron mejoras en la inspección del trabajo. Mediante un panel de regiones subnacionales se analiza el papel cumplido por estos factores en el proceso de formalización. En primer lugar, se confirma que la composición del crecimiento importa para la formalización. Al analizar de manera conjunta los factores económicos (crecimiento y crecimiento sectorial) y los cambios institucionales recientes, se encuentra que —en el período analizado- dichos factores explican la mayor parte del proceso de formalización y que el crecimiento de los sectores intensivos en empleo agrega poder explicativo, mientras que los cambios institucionales no incidieron significativamente a pesar de su magnitud.

PALABRAs CLAVE

CLASIFICACIÓN JEL

AUTOR
Crecimiento económico, empleo, mercado de trabajo, sector informal, modelos econométricos, estudios de caso, política laboral, Perú

J08, J46, 017, 040

Juan Chacaltana es Especialista en economía laboral de la Oficina Regional de la Organización Internacional del Trabajo (огт) para América Latina y el Caribe. 


\section{I}

\section{Introducción}

Los primeros años del siglo XXI fueron excepcionales para la economía del Perú: el producto interno bruto (PIB) creció a una tasa superior al 6\% anual durante más de una década — salvo en el período de la crisis de 2008-2009- lo que es prácticamente inédito en el país. De hecho, en el lapso 2002-2013, el Perú fue el segundo país que más creció en América Latina.

Durante este período se dinamizaron algunos indicadores sociales y económicos. Por ejemplo, la pobreza se redujo a menos de la mitad entre 2002 y 2013, pasando del 54\% al 24\%, disminuyendo incluso en zonas rurales. En el mercado laboral, algunos indicadores también han mostrado evoluciones auspiciosas. En 2013, el desempleo abierto bajó a menos de un $4 \%$ a nivel nacional, los menores índices registrados en las estadísticas peruanas en las últimas décadas. Entre 2002 y 2013, el empleo total creció a una tasa del 2,4\% anual, superior al crecimiento de la población en edad de trabajar (1,8\% anual). Los salarios reales urbanos crecieron a un ritmo de $3,6 \%$ anual y la cobertura de la seguridad social en salud aumentó del $30 \%$ al $59 \%{ }^{1}$.

Probablemente el cambio más significativo fue que la proporción de trabajadores con empleo formal pasó del 20,1\% en 2007 al 26,3\% en 2013, según datos oficiales del Instituto Nacional de Estadística e Informática (INEI, 2014). Si bien se encuentra todavía en un nivel bastante bajo, es notorio que la tasa de este empleo ha aumentado en seis puntos porcentuales, lo que significa que el empleo formal ha crecido notoriamente más que el empleo total en este período. Otro indicador de formalización es el empleo registrado a nivel nacional calculado por el Ministerio de Trabajo y Promoción del Empleo (MTPE) $)^{2}$. Este también ha crecido continuamente

\footnotetext{
$\square$ Las opiniones vertidas en este artículo son de exclusiva responsabilidad del autor y no comprometen necesariamente la opinión de la Organización Internacional del Trabajo (OIT). Asimismo, se agradecen los valiosos comentarios y sugerencias de Janina León, Gustavo Yamada, Gabriel Rodríguez, Jorge Rojas, Patricia Tovar, Rodolfo Cermeño, Ricardo Infante, Jorge Bernedo, Phillipe Marcadent, Rosalía Vásquez-Álvarez, Juan Manuel García, Claudia Ruiz y Florencio Gudiño a una versión previa. Cualquier error u omisión es responsabilidad exclusiva del autor.

${ }^{1}$ OIT (2014). Incluye regímenes no contributivos y semicontributivos.

${ }^{2}$ El índice de empleo registrado permite observar el comportamiento del empleo asalariado en las empresas con 10 y más trabajadores. Se calcula sobre la base de la Encuesta Nacional de Variación Mensual del Empleo (ENVME).
}

desde el año 2002, luego de un relativo estancamiento a fines de la década de 1990. Ello refleja un cambio de tendencia respecto de décadas pasadas, cuando la informalidad usualmente se incrementaba, incluso ante distintos contextos económicos.

Se ha escrito muy poco sobre formalización en países en desarrollo y con alta informalidad como el Perú. La literatura y la discusión académica se han concentrado sobre todo en el análisis de la informalidad. Es más, casi todo lo que se sabe sobre formalización en el Perú se basa en teorías o estudios previos a intervenciones específicas y poco en sus evaluaciones. En este artículo se propone un análisis ex post a dos cambios institucionales importantes: la creación del régimen laboral especial para las micro y pequeñas empresas y el mejoramiento del sistema de inspección laboral. Es decir, se analiza el proceso de formalización ocurrido en un período específico a fin de identificar elementos explicativos y extraer lecciones. Se discuten preguntas tales como: $i$ a qué se debe el cambio de tendencia e incremento en la formalización en el Perú? ¿Es el resultado de las altas tasas de crecimiento observadas? ¿O de la reforma laboral, que creó un régimen laboral especial para las micro y pequeñas empresas y que, por lo tanto, redujo significativamente los costos del trabajo para la mayor parte del mercado laboral asalariado? En particular, ¿cuál ha sido el papel de la composición del crecimiento a nivel sectorial o el aporte de los importantes cambios institucionales que se han producido en este mismo período? En este estudio se analizan todos estos factores de manera conjunta, tratando de identificar el peso relativo de cada uno de ellos en el proceso de formalización observado a nivel de regiones. Dicho proceso es reciente en el Perú y ofrece, además, un caso único donde se pueden analizar comparativamente teorías contrapuestas sobre la formalización. Su análisis permitirá consolidar y profundizar políticas o estrategias de formalización en el marco de un enfoque integrado o multidimensional ${ }^{3}$.

El artículo se organiza de la siguiente manera. En la segunda sección se revisa la literatura existente

\footnotetext{
3 Otras reformas pueden haber contribuido al proceso de formalización observado en el Perú, en particular, las políticas de promoción de las micro, pequeñas y medianas empresas y reformas de simplificación de trámites. Sin embargo, la evaluación de dichas políticas excede el ámbito de este artículo.
} 
relativa a las causas de la informalidad y sus distintos determinantes. En la tercera sección se analizan los cambios económicos e institucionales recientes en el Perú que pueden haber contribuido al proceso de formalización, utilizando a las regiones subnacionales como unidades de análisis durante el período 2002-2012. En la cuarta sección se realiza una estimación econométrica para cuantificar cuáles son los determinantes del proceso de formalización. Finalmente, en la quinta sección se presentan las conclusiones del estudio.

\section{II}

\section{Revisión de la literatura}

Desde que se propuso por primera vez el concepto de informalidad a inicios de los años setenta (Hart, 1972), y por casi cuatro décadas, se ha discutido mucho sobre las causas de la informalidad a nivel mundial, pero no ha habido consenso en su definición o incluso en su medición ${ }^{4}$. Esta falta de consenso conceptual explica, sin duda, el distinto énfasis que cada cual otorga a las recomendaciones de política.

Diversos enfoques o marcos teóricos han sido desarrollados y propuestos como explicación de la informalidad $^{5}$. En un primer grupo de estudios, se la vincula a factores económicos, especialmente a la ausencia de desarrollo productivo, a las características de este, o a ambos. En ese sentido, existe una visión según la cual para el desarrollo económico solo importan los niveles de crecimiento, enfatizando sobre todo en la acumulación de capital físico ${ }^{6}$. La implicación más conocida de estos modelos es que eventualmente habría convergencia entre países, aunque la literatura empírica no ha respaldado esta predicción. En otra visión se sostiene que la composición del crecimiento también resulta importante, dado que este puede ser desigual entre sectores, principalmente debido a la composición de la demanda (Ray, 2010).

En línea con esta segunda visión destacan, por una parte, la aproximación dualista, según la cual el cambio económico se determina no solo por la magnitud del crecimiento, sino también por el traslado de recursos productivos de un sector de subsistencia a un sector capitalista (Lewis, 1954). Doeringer y Piore (1971)

\footnotetext{
4 Kanbur (2009) señala que la literatura al respecto es un caos, que hay "incoherencia conceptual" y que cada quien utiliza una definición distinta.

${ }^{5}$ En numerosos estudios se ha intentado clasificar los diversos enfoques existentes. Véase, por ejemplo, WIEGo (2012).

6 Solimano (1996) relaciona este pensamiento sobre todo con la escuela neoclásica.
}

sostienen que existe un sector de "buenos" empleos y uno de "malos" empleos. Por su parte, Acemoglu (2001) también plantea un modelo de búsqueda de empleo donde hay buenos y malos empleos.

Por otra parte, existe la visión de la transformación productiva o del cambio estructural, según la cual la incorporación del progreso técnico no se difunde de manera homogénea en todos los sectores y ramas de actividad. Más bien, este tiende a concentrarse en ciertos sectores y estratos productivos, sobre todo en los vinculados a la exportación, quedando al margen de este proceso de modernización amplios sectores de la economía. A este proceso se le conoce como "heterogeneidad estructural", que considera las diferencias de productividad entre sectores, su aporte al PIB y el volumen de empleo que generan. Esta heterogeneidad existe entre sectores, pero también en su interior, entre estratos productivos y sobre todo según el tamaño de las empresas. La persistencia de un amplio sector de la fuerza de trabajo en sectores o estratos de baja productividad es una fuente considerable de inequidad en la distribución de los ingresos entre los ocupados, y explica también la informalidad en el empleo (Infante y Sunkel, 2012). Además, estos autores destacan que el enfoque de la heterogeneidad productiva por estrato empresarial (tamaño de empresa) es el núcleo a partir del cual se expande la desigualdad en la sociedad.

Algunos autores enfatizan el papel de la agricultura en la promoción del cambio estructural (De Janvry y Sadoulet, 2010). Otros hacen hincapié en el rol del crecimiento de la manufactura como motor de empleo y productividad (Kaldor, 1961, o Chang, 2007). También hay autores que afirman que un sector de servicios dinámico permite un crecimiento más inclusivo, debido a su intensidad en mano de obra y, sobre todo, cuando va acompañado de políticas educativas y de fomento laboral. Bhagwati y Panagriva (2013) añaden que los servicios modernos pueden ser muy progresivos tecnológicamente. Por ejemplo, los sectores de comercio al por menor, 
financiero o de telecomunicaciones manejan tecnologías modernas. Existe también una amplia literatura en que se exploran los efectos del crecimiento basado en los recursos naturales. McMillan y Rodrik (2011) señalan que a mayor dependencia de los recursos naturales en las exportaciones, mucho menor será la repercusión del cambio estructural en la productividad de la mano de obra. Por el contrario, el crecimiento en los sectores más intensivos en mano de obra y en manufacturas generaría más empleo en los países de ingresos medios.

Existe también la posibilidad de que existan interrelaciones entre el sector formal y el sector informal. Tokman (1978) explora la naturaleza de estas interrelaciones y encuentra que el sector informal y el moderno no son compartimentos estancos, y que hay vasos comunicantes muy activos tanto en el mercado de bienes como en el de trabajo. En el caso peruano, León y Cermeño (1990) hacen un recuento de los principales planteamientos sobre las interrelaciones entre los sectores formal e informal en América Latina y el Perú. Al analizar el caso de las microempresas manufactureras de Lima, estos autores encuentran que todas las microempresas, en particular las manufactureras, están muy interrelacionadas con el resto de la economía, sobre todo con el sector productivo moderno (por la vía de compra de insumos) y con los consumidores finales (que son sus principales clientes, en especial los de estratos de bajos ingresos). Portes, Castells y Benton (1989) proponen una visión donde la informalidad está integrada a los sectores modernos a través de procesos de descentralización productiva, principalmente por intermedio de la subcontratación de actividades tanto a nivel nacional como internacional, por lo que la empresa subcontratada tendrá trabajadores no amparados por la legislación laboral con el propósito de reducir sus costos y con ello poder operar con tarifas bajas.

Un segundo grupo de explicaciones se asocia a factores institucionales. Aquí destaca el conocido enfoque basado en la legalidad de De Soto y otros (1986), originalmente desarrollado tomando como base la realidad peruana. En este enfoque se resalta que ante la insuficiente demanda de empleo formal y los altos costos en dinero y tiempo que implican los largos y engorrosos trámites para constituir una empresa formal, y debido al escaso capital con que cuentan, los informales se ven obligados a operar con escasos medios y con niveles de productividad e ingresos muy bajos. Además, estos trabajadores generalmente no poseen título de dominio de su terreno, propiedades y activos productivos, por lo que no pueden acceder al sistema financiero. En esta visión, los informales constituirían un potencial para el desarrollo, de modo que la desregulación de procedimientos y trabas burocráticas resulta esencial para desplegar las potencialidades de los trabajadores pobres.

Una variante de esta visión es aquella que plantea que la informalidad proviene de una decisión voluntaria del trabajador o empresario. Este decide operar fuera de las normas legales luego de un análisis comparativo entre los beneficios de la formalidad y sus costos, en términos de registro, tributación, salarios, seguridad social, entre otros (Fields, 1990; Perry y otros, 2007; Maloney, 1999). En el caso peruano, Yamada (1996) encuentra evidencia de elección voluntaria entre los autoempleados informales. En la misma línea, Levy (2008) añade que la existencia de programas de protección social, sobre todo de aquellos de tipo no contributivo, podría generar incentivos para optar por la informalidad.

Otra visión — también de tipo institucional — tiene que ver con la debilidad de la administración pública, en particular, en relación con los sistemas de inspección y control, y la corrupción existente. Kanbur (2009) enfatiza que hace falta una teoría del cumplimiento efectivo de la ley, tema muy relevante en América Latina, donde en muchos casos se promulgan leyes, pero no se cumplen. En este sentido, como determinantes de la informalidad, Loayza (2013) incluye los siguientes factores: la capacidad del gobierno para hacer cumplir las normas (índice de prevalencia de la ley y el orden), un índice de libertad económica como proxy de restricciones impuestas por el marco normativo y legal, el promedio de escolaridad para representar el desarrollo de la educación, la calificación de la fuerza laboral, un índice de variables sociodemográficas y el peso de la agricultura en el PIB.

Naturalmente, cada línea de pensamiento conduce a conclusiones y recomendaciones de política diferentes $\mathrm{y}$, en algunos casos, hasta opuestas. Afortunadamente, en las últimas décadas se produjeron avances en esta discusión que dejan ver algún nivel de consenso. En 1993, en la Xv Conferencia Internacional de Estadísticos del Trabajo (XV CIET) se definieron las dimensiones del concepto de "sector informal" y se lo asoció a las características de la unidad económica ${ }^{7}$. Posteriormente, en 2003, la XVII Conferencia Internacional de Estadísticos del Trabajo (XVII CIET) complementó esta definición e incorporó el concepto de "empleo informal", basado

\footnotetext{
${ }^{7}$ Nótese que este concepto difiere del "sector informal”, muy utilizado en América Latina por el Programa Regional del Empleo para América Latina (PREALC), y que se basaba en formas de producción de baja productividad, entre ellas, empresas de menor tamaño, trabajadores por cuenta propia no calificados y el trabajo doméstico.
} 
en las características del puesto de trabajo ${ }^{8}$. La unión de ambos conceptos genera la denominada "economía informal" . En todo caso, esto implica que el empleo informal existe no solo en el sector informal, sino también fuera de él, aunque cada uno de estos componentes tenga un peso relativo diferente en cada país. Además, es claro que las políticas que se aplican al empleo informal en el sector informal son distintas a las aplicables en el empleo informal fuera del mismo.

Esto, junto con la abrumadora evidencia internacional de que la informalidad es altamente heterogénea, han abierto la posibilidad de pensar las políticas de formalización en términos más amplios. La Conferencia Internacional del Trabajo (CIT) propuso en sus discusiones de 2014 y 2015 un enfoque integrado para facilitar la transición de la informalidad a la formalidad. Sobre la base de estas discusiones, se adoptó la Recomendación sobre la transición de la economía informal a la economía

${ }^{8}$ Para una mayor discusión, véase oIt (2013).

9 OIT (2002). formal (OIT, 2015), lo que marca el inicio de un consenso mundial en cuanto a recomendaciones de política. Esto implica reconocer que la informalidad es tan heterogénea que todos los factores que se pueda pensar que la causan deben tener algo o parte de razón; que no todos los informales se hallan en esa condición por la misma causa, y que las causas de la informalidad son muchas y operan en múltiples dimensiones. Por esta razón, cuando se piensa en políticas de formalización, se requiere un enfoque multidimensional, que involucre a muchos actores operando de manera coordinada. Visto así, resulta limitado pensar que una medida única o aislada pueda impulsar la formalización en todos los países y circunstancias. Esto implica también que los diferentes elementos que causan la formalidad difieren entre los diferentes países, territorios o sectores. Es decir, los determinantes finales de la informalidad —o formalidad — en un país específico, tienen que ser establecidos de manera empírica y no teórica, de acuerdo con cada circunstancia. En particular, es necesario establecer empíricamente y en cada caso cuáles de los factores asociados a la formalidad (o a la informalidad) tienen mayor influencia respecto de otros.

\section{III}

\section{Hechos estilizados, el caso peruano}

Perú siempre ha sido considerado un país de alta informalidad. Según datos oficiales del Instituto Nacional de Estadística e Informática (INEI, 2014), que ha elaborado una Cuenta Satélite de la Economía Informal en el Perú ${ }^{10}$, el sector informal —medido de acuerdo con las características de las unidades económicas- explicaba el 19\% del PIB y el $61 \%$ del total del empleo en el año $2007^{11}$. Asimismo, el empleo informal —que incluye empleo informal en el sector informal, pero también empleo informal en el sector formal y empleo informal en el sector hogares- ascendió al 73,7\% a nivel nacional en 2013. La información sobre empleo informal, en el

\footnotetext{
${ }^{10}$ Véase INEI (2014). Esta Cuenta Satélite de la Economía Informal es consistente con el Sistema de Cuentas Nacionales del país. El empleo informal es estimado a partir de jornadas equivalentes, con fines de compatibilidad con Cuentas Nacionales (período 2007 a 2013).

11 Existen otras estimaciones del aporte del sector informal al PIB, aunque con métodos indirectos. La aproximación del INEI es directa. En cualquier caso, si estas cifras son correctas, la productividad del sector formal multiplica por ocho veces la del sector informal.
}

caso peruano, se obtiene de la Encuesta Nacional de Hogares (ENAHO). Esto permite conocer que alrededor de dos de cada tres trabajadores con empleo informal trabaja en unidades económicas del sector informal.

\section{1. ¿Formalización en el Perú?}

Casi la totalidad de los estudios académicos sobre este tema en el Perú han tratado de explicar el fenómeno de la informalidad y, en particular, su constante incremento ${ }^{12}$. No es para menos. En décadas pasadas, lo usual ha sido el aumento de la informalidad en el mercado del trabajo peruano $^{13}$. En ese sentido, probablemente el hecho más

\footnotetext{
${ }^{12}$ Chong, Galdo y Saavedra (2007) registran un incremento persistente de la informalidad en el período 1986-2001, utilizando diversas definiciones de informalidad.

13 A diferencia del análisis de la informalidad, el estudio de los procesos de formalización es un tema de reciente interés académico a nivel internacional. Véanse Berg (2010) para el caso del Brasil y Bertranou y Casanova (2014) para la Argentina.
} 
novedoso en este mercado laboral en años recientes sea el inicio de una tendencia a la formalización, lo que constituye un cambio en una tendencia de largo plazo que vale la pena analizar.

Diversos indicadores confirman este cambio de tendencia (véase el gráfico 1). Por una parte, como se ha señalado, según los datos oficiales del INEI, el porcentaje de trabajadores con empleo formal pasó del $20 \%$ en 2007 al 26\% en 2013 a nivel nacional, incluidos aquí los trabajadores urbanos y rurales de todos los sectores económicos (medido en el eje izquierdo del gráfico 1). Asimismo, el MTPE calcula un índice de empleo registrado desde el año 1997 e indica que este creció continuamente desde el año 2002 (medido en el eje derecho del gráfico 1), luego de un relativo estancamiento a fines de la década de 1990 e inicios de $2000^{14}$. Otros datos de registros administrativos son aún más auspiciosos. Registros de la seguridad social indican que los afiliados y cotizantes al Seguro Social de Salud (EsSalud) pasaron de 1,6 millones en 2002 a 4,3 millones en el último trimestre de 2013, mientras que los cotizantes a algún sistema de pensiones pasaron de 1,5 millones en el año 2002 a 4 millones en 2013. Asimismo, el registro de trabajadores en planilla pasó de menos de un millón en el año 2000 a 3,1 millones en 2013.

\footnotetext{
${ }^{14}$ El índice de empleo registrado permite observar el comportamiento del empleo asalariado en las empresas de diez y más trabajadores. Se calcula sobre la base de la Encuesta Nacional de Variación Mensual del Empleo (ENVME).
}

GRÁFICO 1

Perú: indicadores oficiales de formalización

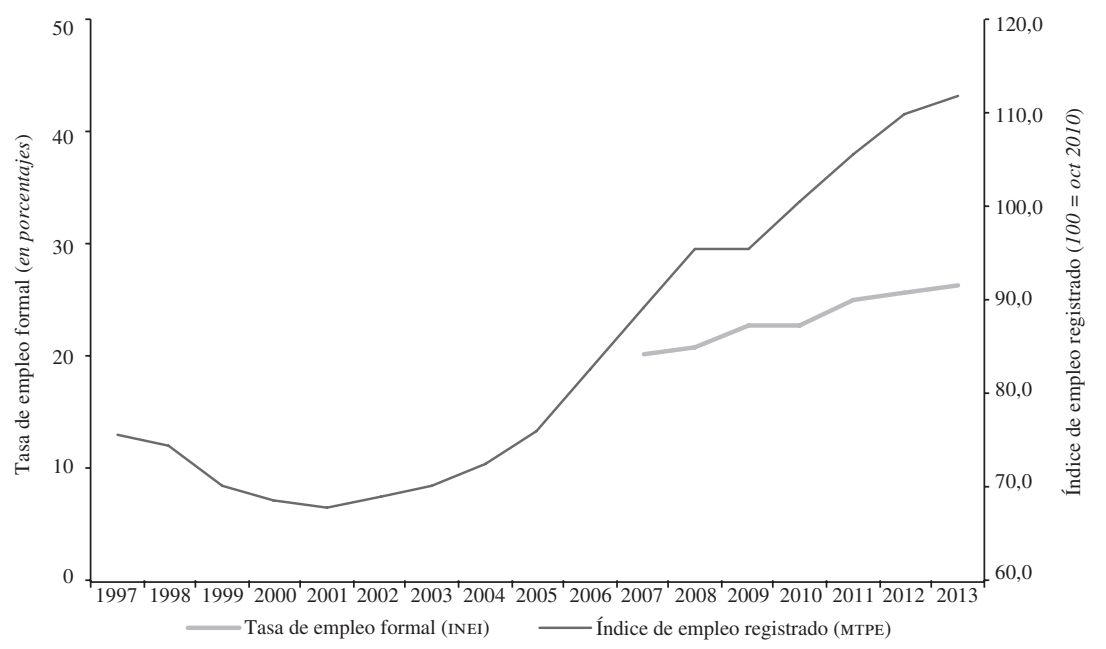

Fuente: Elaboración propia sobre la base de Instituto Nacional de Estadística e Informática (INEI), Producción y empleo informal en el Perú. Cuenta satélite de la economía informal 2007-2012, Lima, 2014 y estadísticas del Ministerio de Trabajo y Promoción del Empleo (MTPE).

Sobre la base de estimaciones propias utilizando una metodología similar a la empleada por el INEI para un período más largo $(2002-2012)^{15}$, se observa que el incremento de la tasa de empleo formal ha ocurrido sobre todo entre los trabajadores asalariados, para

\footnotetext{
15 Metodología basada en las directrices de medición de la XVII Conferencia Internacional de Estadísticos del Trabajo (OIT, 2013). La diferencia con la estimación de INEI (2014) radica en que esta última se basa en el número de empleos equivalentes (calculados sobre la base de la duración de las jornadas) con fines de compatibilidad con el Sistema de Cuentas Nacionales.
}

quienes la tasa de formalidad pasó del $41 \%$ al $50 \%$ entre esos años (véase el cuadro 1). Esta tendencia es muy importante porque, en el mismo período, la proporción de trabajadores asalariados en el empleo total también aumentó del 39\% al 45\%. Dentro de los asalariados se observa que los mayores incrementos en las tasas de formalidad ocurrieron entre los trabajadores de empresas con más de diez trabajadores, donde pasó del $61 \%$ al $71 \%$, y además la participación de este grupo en el empleo total subió del $23 \%$ al $29 \%$. En el caso de las empresas más pequeñas, el incremento de la tasa de formalidad fue de un $13 \%$ a un $15 \%$, y su participación en el empleo total pasó del $16 \%$ al $17 \%$. 
Perú: evolución de la tasa de empleo formal, 2002 y 2012 (En porcentajes)

\begin{tabular}{|c|c|c|c|c|}
\hline & \multicolumn{2}{|c|}{2002} & \multicolumn{2}{|c|}{2012} \\
\hline & $\begin{array}{l}\text { Tasa de empleo } \\
\text { formal }\end{array}$ & $\begin{array}{c}\text { Participación } \\
\text { en el empleo total }\end{array}$ & $\begin{array}{l}\text { Tasa de empleo } \\
\text { formal }\end{array}$ & $\begin{array}{c}\text { Participación } \\
\text { en el empleo total }\end{array}$ \\
\hline \multicolumn{5}{|l|}{ Total } \\
\hline Empleador & 34,1 & 5,1 & 39,9 & 5,4 \\
\hline Asalariado de empresa & 40,7 & 39,1 & 50,1 & 45,4 \\
\hline 1 a 10 & 12,7 & 16,3 & 15,2 & 16,7 \\
\hline Más de 10 & 60,9 & 22,7 & 70,5 & 28,7 \\
\hline Asalariado de hogar & 10,0 & 3,5 & 19,3 & 2,6 \\
\hline Cuenta propia & 4,3 & 35,4 & 4,6 & 34,8 \\
\hline Trabajador familiar auxiliar & 0,0 & 16,7 & 0,0 & 11,6 \\
\hline Otro & 21,3 & 0,2 & 16,3 & 0,3 \\
\hline Total & 19,6 & 100,0 & 27,1 & 100,0 \\
\hline
\end{tabular}

Fuente: Elaboración propia sobre la base de Instituto Nacional de Estadística e Informática (INEI), Encuesta Nacional de Hogares (ENAHO), varios años.

Una evolución también relevante ha ocurrido con el empleo informal de los asalariados de hogares (que realizan trabajo doméstico), cuya tasa de formalidad subió del 10\% al 19\%, aunque su participación en el empleo se redujo de un $4 \%$ a un $3 \%$. En el caso de los trabajadores por cuenta propia, las tasas de formalidad pasaron de un 4,3\% a un 4,6\% y su participación en el empleo total no se alteró, manteniéndose en el $35 \%$. A pesar de todos estos cambios, los trabajadores por cuenta propia, los trabajadores de empresas con hasta diez ocupados, y los trabajadores domésticos explican más de dos tercios del empleo informal total.

$\mathrm{El}$ hecho de que el incremento del empleo formal se haya concentrado en los asalariados antes que en los trabajadores por cuenta propia resalta que, en ambos casos, las causas de la informalidad y de las políticas pertinentes son diferentes. Esto sugiere, además, que el análisis de cada caso deba hacerse por separado.

\section{Cambios económicos e institucionales recientes}

Algunos cambios económicos e institucionales pueden estar vinculados a este cambio de tendencia en la formalización del empleo.

En primer lugar, se destaca el alto crecimiento económico que ha alcanzado la economía peruana, precisamente a partir del año 2002. Uno de los principales debates en la literatura sobre informalidad se refiere a su carácter procíclico o anticíclico. Si es anticíclico, existirían elementos para considerar que se trata de una suerte de "colchón de ajuste" ante la falta de oportunidades en el sector formal. Si hay elementos procíclicos, existiría la posibilidad de elección voluntaria. En el caso peruano reciente, este crecimiento ha sido elevado y sostenido, alcanzando una tasa de crecimiento promedio anual del $6,1 \%$ entre 2002 y 2013. En comparación con lo ocurrido en décadas previas, en la década de 1990 la economía peruana creció alrededor del $3 \%$ anual y en la década de 1980 el crecimiento fue prácticamente nulo. El crecimiento peruano reciente se ha asociado principalmente a un contexto internacional altamente favorable, tanto debido a los altos precios de productos básicos de exportación y a mejores términos de intercambio, así como por la disponibilidad de financiamiento externo y de inversión extranjera directa (IED). También se ha relacionado con políticas macroeconómicas, tales como el establecimiento de una meta de inflación para la política monetaria, la acumulación de reservas internacionales, la flexibilidad del tipo de cambio y políticas fiscales contracíclicas (MEF, 2011). La productividad —una de las variables más enfatizadas en las discusiones sobre formalizacióncreció a un ritmo del 3,3\% anual en el período 2000-2011 (Infante, Chacaltana e Higa, 2014). Si bien esta tasa no es tan alta como la observada en algunos países asiáticos en igual período, se encuentra entre las más elevadas de América Latina y el Caribe ${ }^{16}$.

\footnotetext{
16 Para los siguientes años se espera una mayor incertidumbre en el contexto internacional y se discuten actualmente los efectos que este cambio podría tener en la tasa de crecimiento del país. Existe relativo consenso, por ejemplo, en que los precios de las materias primas relevantes para el Perú (notablemente el caso del cobre) no crecerán en la forma y niveles en que lo hicieron en la década anterior.
} 
En segundo lugar, el tema de la composición sectorial del crecimiento suele vincularse a la informalidad y, por lo tanto, a la formalización. Esto tiene que ver con la existencia de una elevada heterogeneidad productiva en la economía peruana, que se expresa tanto entre sectores económicos como en el interior de ellos. De hecho, quizás la característica estructural más notoria de la economía peruana sea la elevada heterogeneidad y dispersión productiva, unidas a una manifiesta desarticulación entre aquellos sectores más productivos y los menos productivos. Esto se puede apreciar claramente en el cuadro 2, donde se observa que en 2007 la productividad máxima (minería) superó 50 veces a la productividad mínima (sector agropecuario y pesca).

Perú: estructura de la producción y el empleo según sector informal o formal, 2007

\begin{tabular}{|c|c|c|c|c|c|}
\hline & \multirow{2}{*}{$\begin{array}{c}\text { Participación del sector } \\
\text { informal en el PIB } \\
(\%)\end{array}$} & \multirow{2}{*}{$\begin{array}{c}\text { Participación del sector } \\
\text { informal en el empleo } \\
(\%)\end{array}$} & \multicolumn{3}{|c|}{ Productividad laboral (S/. 2007) } \\
\hline & & & Total & Formal & Informal \\
\hline Total & 19 & 61 & 19125 & 39,722 & 5,957 \\
\hline Otros servicios (inc. gobierno) & 6 & 13 & 27714 & 29,944 & 12,791 \\
\hline Manufactura & 13 & 39 & 30141 & 42,988 & 10,047 \\
\hline Minería & 2 & 30 & 224961 & 314,945 & 14,997 \\
\hline Comercio & 32 & 65 & 11910 & 23,139 & 5,863 \\
\hline Transportes & 37 & 73 & 23807 & 55,549 & 12,066 \\
\hline Agropecuario y pesca & 89 & 98 & 4620 & 25,411 & 4,196 \\
\hline Construcción & 25 & 54 & 23820 & 38,838 & 11,028 \\
\hline Restaurantes y alojamiento & 47 & 67 & 8955 & 14,382 & 6,282 \\
\hline
\end{tabular}

Fuente: Elaboración propia sobre la base de Instituto Nacional de Estadística e Informática (INEI), Producción y empleo informal en el Perú. Cuenta satélite de la economía informal 2007-2012, Lima, 2014.

Nota: PIB: Producto interno bruto; Inc. gobierno: Incluye servicios ofrecidos por el gobierno.

Al mismo tiempo, dentro de los sectores la diferencia también es notable: la productividad de la minería formal es 15 veces mayor que la de la minería informal. En el gráfico 2 llama la atención también que - sin contar la minería - el sector más productivo del sector informal (Otros servicios) tenga menor nivel de productividad que el menos productivo del sector formal (Restaurantes y hoteles). Esto habla de un país dividido y de una estructura de producción poco incluyente y potencialmente generadora de informalidad ${ }^{17}$.

Con respecto a las tendencias, los datos oficiales de producción dan cuenta de cambios en la composición del crecimiento (véase el cuadro 3). En el período previo a 2002 se observaron tasas de crecimiento muy elevadas en sectores como la minería, incluso en el período de crisis internacional que se inició en 1998. Esta composición se modificó a partir del año 2003, cuando crecen con mayor intensidad sectores como la manufactura o la construcción.

17 Távara, González de Olarte y Del Pozo (2014) analizan la heterogeneidad productiva del Perú en el largo plazo y hallan que esta crece tanto en períodos de crecimiento como de crisis. Encuentran también que la mayor parte de los servicios (financieros y no financieros) son producidos y consumidos por el sector de las grandes empresas. Lo mismo ocurre con la energía.
Los datos de recomposición dentro de los sectores son menos frecuentes. Aun así, algunos estudios han permitido evidenciar su importancia. Infante, Chacaltana e Higa (2014) estiman que del 3,3\% anual de crecimiento de la productividad en el período 20002011, un 2,8\% se debe a las grandes empresas (de más de 200 trabajadores), en tanto que el $0,5 \%$ restante a las micro, pequeñas y medianas empresas. Tello (2012) analiza el comportamiento de la productividad en el período 2002-2007 y encuentra que es la reasignación de empleo entre sectores, antes que los cambios en la productividad dentro de ellos, lo que mejor explica los cambios en la productividad peruana.

Por otra parte, también se han producido cambios institucionales importantes en la década pasada. Es probable que el más importante en tal sentido haya sido la reforma que creó regímenes laborales especiales, es decir, regulación específica para ciertos colectivos de trabajadores. Aquí destaca nítidamente la creación del régimen laboral especial para las micro y pequeñas empresas, denominada Ley de Promoción y Formalización de la Micro y Pequeña Empresa (Ley MYPE) ${ }^{18}$. Ya en la década de 1990 se había

\footnotetext{
18 Vale la pena mencionar que en el año 2000 se creó asimismo el Régimen de Promoción Agraria que incluye también los regímenes
} 
GRÁFICO 2

Perú: heterogeneidad productiva, formal e informal, 2007

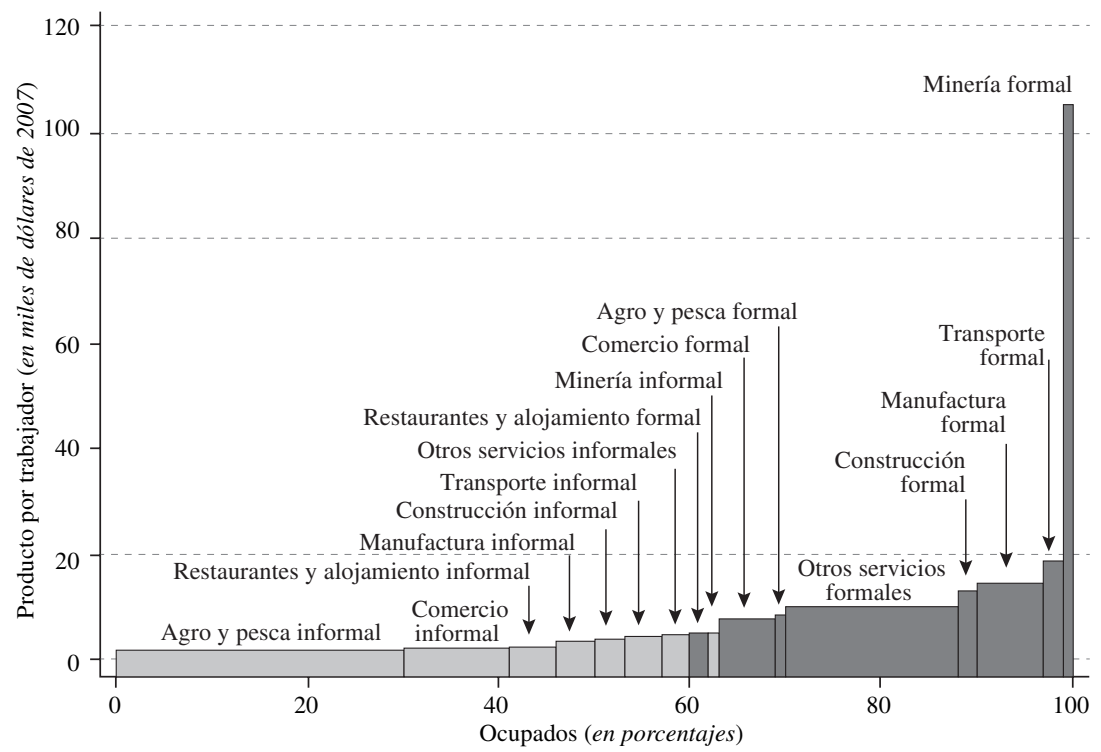

Fuente: Elaboración propia sobre la base de Instituto Nacional de Estadística e Informática (INEI), Producción y empleo informal en el Perú. Cuenta satélite de la economía informal 2007-2012, Lima, 2014.

CUADRO 3

Perú: crecimiento promedio anual del PIB por sectores económicos, cuatro períodos entre 1993 y 2012

(En porcentajes)

\begin{tabular}{lcccc}
\hline & $1993-1997$ & $1998-2002$ & $2003-2007$ & $2008-2012$ \\
\hline Agricultura, caza y silvicultura & 8,4 & 4,7 & 3,7 & 4,9 \\
Pesca & 0,2 & 3,0 & 5,8 & 0,5 \\
Minería & 8,1 & 8,1 & 4,6 & 2,2 \\
Manufactura & 6,3 & 1,5 & 7,4 & 4,4 \\
Electricidad y agua & 8,7 & 3,9 & 5,8 & 5,9 \\
Construcción & 16,2 & $-3,3$ & 9,7 & 11,4 \\
Comercio & 7,6 & 0,8 & 7,2 & 7,5 \\
Transportes y comunicaciones & 6,8 & 1,4 & 9,5 & 7,2 \\
Restaurantes y hoteles & 6,4 & 0,9 & 5,7 & 8,0 \\
Otros servicios & 4,9 & 1,5 & 5,5 & 6,7 \\
Total & 6,9 & 1,8 & 6,5 & 6,4 \\
\hline
\end{tabular}

Fuente: Elaboración propia sobre la base de cuentas nacionales del Instituto Nacional de Estadística e Informática (INEI).

Nota: PIB: Producto interno bruto.

producido una reforma en la contratación y el despido a nivel del régimen de contratación general ${ }^{19}$. La creación de regímenes especiales es una nueva tendencia normativa y ha ocurrido sobre todo en el nuevo siglo. La Ley MYPE

laboral y tributario especiales, aplicables a empresas agrícolas de cualquier tamaño. Para mayor información, véase Chacaltana (2007).

19 Chacaltana (2001) encuentra que las reformas laborales de la década de 1990, que flexibilizaron las modalidades de contratación y despido, no estuvieron acompañadas de mejoras en la formalización. aprobada en 2003 redujo de manera drástica los costos no salariales para trabajadores de microempresas (hasta diez trabajadores) a menos de la cuarta parte de lo que se establece en el régimen general, así como el costo de despido a la tercera parte del régimen general ${ }^{20}$. Cabe destacar que en 2008 , el régimen especial de la Ley

${ }^{20}$ Existe discusión sobre el concepto de "costos no salariales". Para algunos, el pago de las vacaciones, por ejemplo, forma parte del salario. 
MYPE fue ampliado y se creó un régimen intermedio para empresas de hasta 100 trabajadores, que reduce los costos del trabajo en alrededor de la mitad de los existentes en el régimen general ${ }^{21}$. Este régimen entró en vigencia a inicios de 2009.

Dado que las microempresas generan más del $70 \%$ del empleo asalariado en el Perú, estas reformas implicaron un cambio notorio en los costos del trabajo promedio (véase el gráfico 3). En términos ponderados, los denominados costos laborales no salariales se redujeron del $54 \%$ al $17 \%$ como proporción del salario en el año $2003^{22}$. A pesar de su magnitud, estos regímenes han sido objeto de pocos estudios. Chacaltana (2008) analiza los primeros cuatro años del régimen para las microempresas y encuentra una cobertura mínima. Jaramillo (2013) llega a resultados similares. En tanto que Díaz (2014) agrega que la formalización de los últimos años ocurrió con mayor énfasis en el sector de las grandes empresas, antes que en el de las micro y pequeñas empresas (MYPE).

21 Cálculos a partir de la Ley $\mathrm{N}^{\circ} 30288$ publicada en el diario oficial El Peruano (16 de diciembre de 2014).

22 Cabe enfatizar que en 2013 se amplía aún más este régimen y se elimina el límite del número de trabajadores como elemento de aplicabilidad de la ley. Los cálculos se han hecho utilizando datos de la Ley $\mathrm{N}^{\circ} 30288$ publicada en el diario oficial El Peruano (16 de diciembre de 2014).
Finalmente, otro elemento relacionado con la formalización es la capacidad del Estado para hacer cumplir sus propias normas ${ }^{23}$. La capacidad inspectiva peruana siempre se ha considerado $-\mathrm{y}$ de hecho ha sido- débil. No obstante, en la última década se produjeron cambios importantes en este sentido. La fuerza del Estado para hacer cumplir sus normas se manifiesta a través de la probabilidad de detección de infracciones laborales. Esta depende de la cantidad de inspectores, de la tecnología con que se realiza la inspección y su organización. En todos estos ámbitos ha habido mejoras. Se ha incrementado el número de inspectores, pero sobre todo se han producido cambios en la tecnología de la inspección. En 2006 se firmó un acuerdo entre el Ministerio de Trabajo y Promoción del Empleo y la Superintendencia Nacional de Administración Tributaria (SUNAT) mediante el cual se creó el sistema de Planilla Electrónica. En el Perú, las empresas deben enviar sus planillas al Estado, incluyendo información del trabajador, salarios, modalidad contractual y otros beneficios. Antes del acuerdo, las planillas de las empresas debían ser enviadas cada año, impresas y en físico, al MTPE. Con el sistema de Planilla Electrónica,

\footnotetext{
${ }^{23}$ Kanbur (2009) menciona que el tema de hacer cumplir las normas ha sido postergado en la literatura económica y que se necesita una teoría al respecto.
}

GRÁFICO 3

Perú: índice de costo laboral por régimen y promedio ponderado, 2000-2013

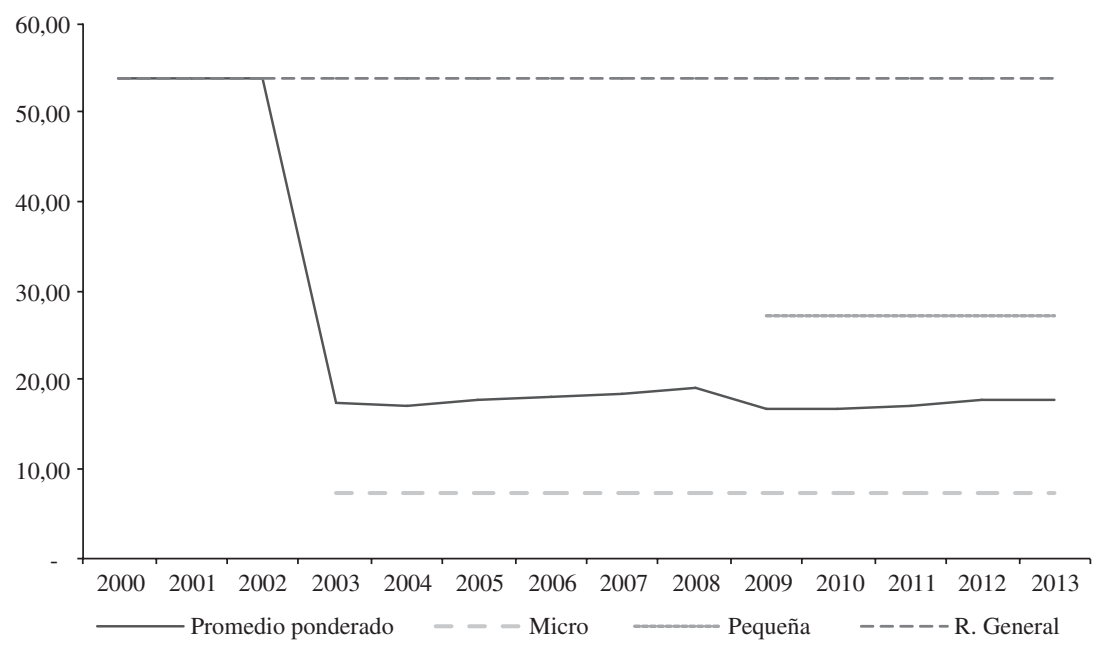

Fuente: Elaboración propia sobre la base del diario oficial El Peruano, "Ley N³0288”, 16 de diciembre de 2014, Lima; Instituto Nacional de Estadística e Informática (INEI) y Encuesta Nacional de Hogares (ENAHO), varios años.

Nota: El promedio ponderado se calculó tomando en cuenta la participación de trabajadores por tamaño de empresa y el costo no salarial según el tamaño de esta. R. General: Régimen general. 
las planillas se deben enviar mensualmente a la SUNAT, junto con la declaración de impuestos. Dado que la SUNAT ha tenido una mayor capacidad inspectiva que el MTPE, esto debería haber implicado un aumento en la probabilidad de detección de infracciones laborales, al menos al nivel existente en la SUNAT ${ }^{24}$.

Existen posiblemente otros elementos, pero estos son los más destacados o recurrentes en la discusión académica y política en el Perú. En escasos estudios se

${ }^{24}$ La información de la Planilla Electrónica está disponible para el servicio de inspecciones. ha realizado un análisis combinado de múltiples factores en relación con la formalidad (o informalidad $)^{25}$. Por lo general, los estudios se han concentrado en alguno de estos elementos. De hecho, es posible que, por separado, cada uno de estos elementos presente algún grado de correlación y significancia. El desafío es ver si estos aún persisten en el análisis comparado, controlando por otras explicaciones posibles.

25 Véanse, por ejemplo, Machado (2012); Loayza (2013), y Verdera (2014).

\section{IV}

\section{Análisis empírico 26}

En esta sección se procura explicar el incremento de la formalización ocurrido en el Perú entre los años 2002 y 2012 a nivel de regiones. En una primera etapa se analiza la relación entre formalización y crecimiento económico, prestando especial atención al papel de su composición, es decir, al crecimiento de cada sector económico en cada región. En una segunda etapa, además del crecimiento económico y el crecimiento sectorial, se incluye una variable proxy para las reformas institucionales con la finalidad de establecer su aporte comparativo.

Se cuenta para ello con información de tipo panel a nivel de las 24 regiones del país y para los 11 años comprendidos en este intervalo de tiempo. A fin de analizar el papel de la composición del crecimiento económico por sectores, en el panel se incluye además información sobre el valor agregado por trabajador para ocho sectores económicos en cada región (Agricultura y pesca, Minería, Manufactura, Construcción, Comercio, Transportes y comunicaciones, Restaurantes y hoteles, y Otros servicios, que comprenden la administración del Gobierno así como servicios sociales) ${ }^{27}$.

\footnotetext{
${ }^{26}$ En la cuarta sección se utiliza información de la tasa de empleo registrado proveniente de la Encuesta Nacional de Variación Mensual del Empleo del MTPE (2002-2012) para el ejercicio econométrico, a menos que se indique lo contrario.

27 El valor agregado regional es el PIB regional menos impuestos y derechos de importación, medido en precios constantes de 1994. Este se divide entre el total de trabajadores de la región para calcular el valor agregado por trabajador. En el momento de edición de este artículo, solo se contaba con información desagregada por sector y región hasta el año 2012.
}

Para medir la formalidad se pueden emplear diversos indicadores. A menos que se señale lo contrario, se utiliza el indicador de tasa de empleo registrado en cada región, definido como el porcentaje de trabajadores que las empresas reportan sobre el total de trabajadores en una región ${ }^{28}$. Se cuenta con información para 15 regiones en el período 2002-2007 y para todas las regiones de 2008 a 2012. Se trata, por lo tanto, de un panel no balanceado.

La información sobre producción y su composición sectorial se ha obtenido del Compendio Estadístico del Perú, que publicó el INEI en 2013. Esto permite un total de 264 observaciones para cada observación sectorial para los datos de producción.

\section{Crecimiento y formalización: la composición del crecimiento sí importa}

La primera constatación es que efectivamente existe una relación directa entre formalización y crecimiento del producto. Esto se puede apreciar en el gráfico 4, donde se correlaciona la tasa de empleo registrado de cada región con el valor agregado regional por trabajador. Se observa también que esta relación positiva tiene una alta varianza, sobre todo en los niveles más altos de valor agregado regional por trabajador (panel

\footnotetext{
${ }^{28}$ El Ministerio de Trabajo y Promoción del Empleo del Perú (MTPE) gentilmente nos permitió acceso a los valores absolutos de este indicador proveniente de la Encuesta Nacional Mensual de Variación del Empleo (ENVME) y se pudo construir la tasa de empleo registrado (empleo asalariado en empresas de diez y más trabajadores) como proporción del empleo total en cada región.
} 
A del gráfico 4). Nótese también que esta relación cambia en los tramos más altos, cuando se retira a Moquegua del análisis (panel B del gráfico 4), que es una región donde el valor agregado por trabajador es alto — debido a la presencia de la minería de cobre-, pero al mismo tiempo la informalidad en el empleo es elevada porque la mayor parte de su fuerza de trabajo es agrícola. Esta observación es relevante porque plantea la posibilidad de que existan efectos fijos regionales que es necesario controlar.

GRÁFICO 4

Perú: relación entre tasa de empleo registrado y valor agregado por trabajador, por regiones, 2012

(En porcentajes)

A. Todas las regiones

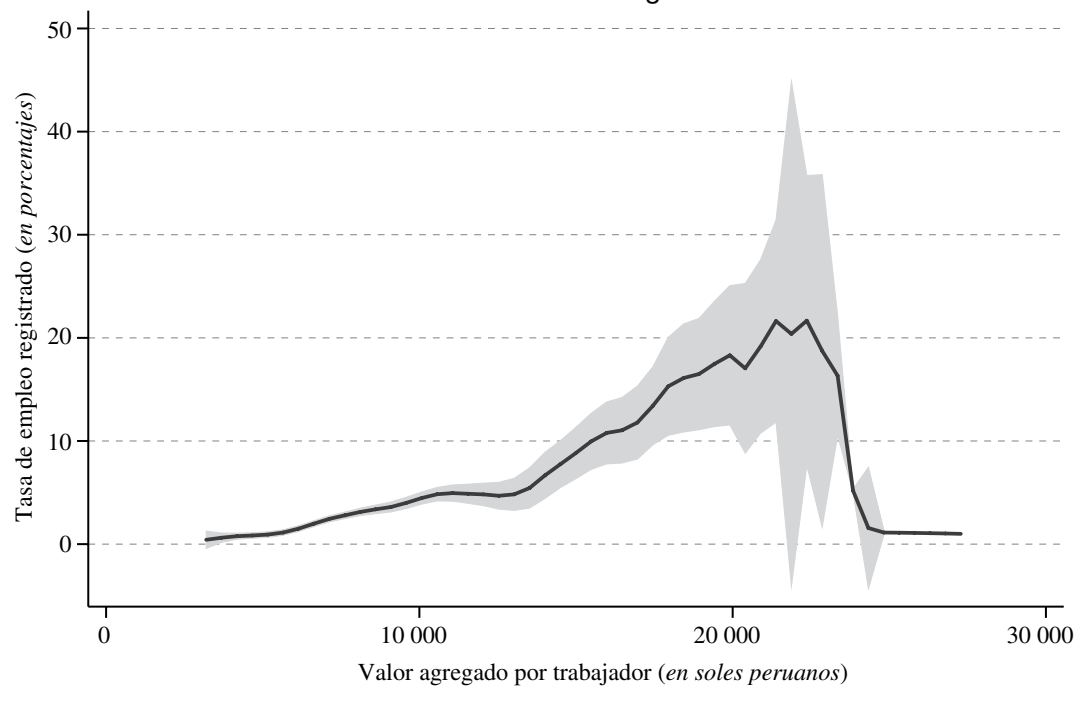

B. Regiones sin Moquegua

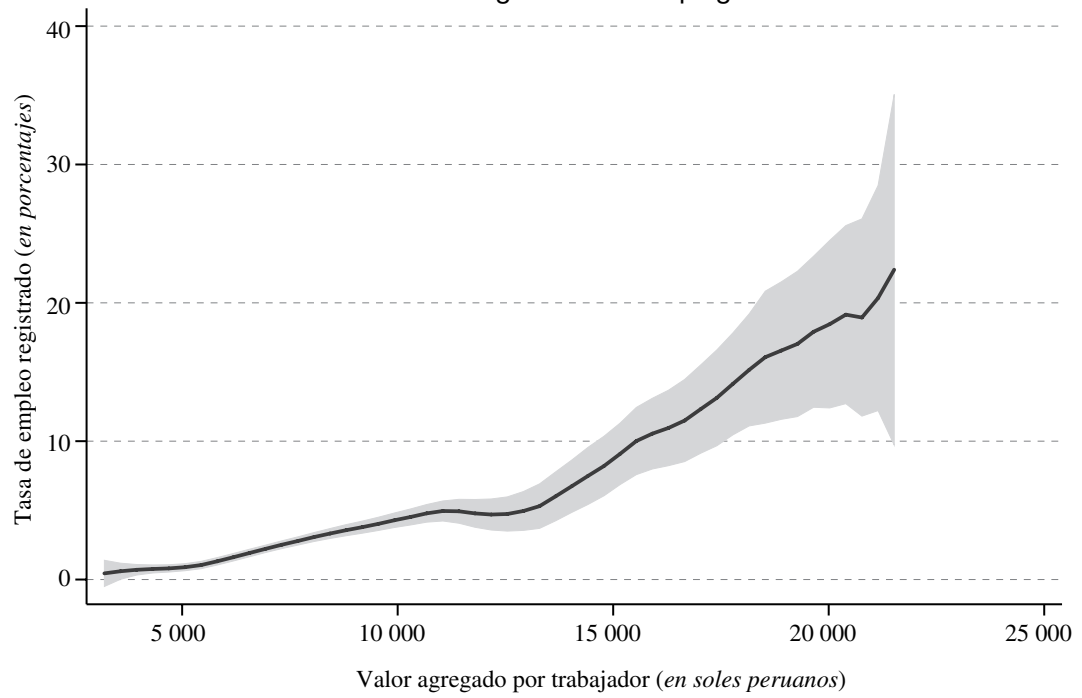

Fuente: Elaboración propia sobre la base de información del Instituto Nacional de Estadística e Informática (INEI) y del Ministerio de Trabajo y Promoción del Empleo (MTPE). 
En todo caso, la correlación simple entre tasa de empleo registrado y valor agregado por trabajador tiene alta varianza. Por consiguiente, debe haber otros factores explicativos de los niveles de formalización y el crecimiento de este indicador. Una primera posibilidad es que, además del crecimiento económico, su composición también sea importante para la formalización. La hipótesis en este caso sería que el tipo de crecimiento económico y, en particular, su composición sectorial, tiende a generar diferentes resultados en términos de formalización. Es decir, la composición sectorial del crecimiento no sería neutral en términos de generación de empleo formal. La transformación productiva ayudaría a explicar y a extender el empleo formal.

Una primera forma de aproximarse a este análisis consiste en descomponer el cambio en las tasas de formalidad, identificando el aporte del cambio sectorial ${ }^{29}$. Se parte por definir la tasa de empleo formal como una suma ponderada de aportes sectoriales:

$$
\tau_{t}=\sum \tau_{i t} \cdot \theta_{i t}
$$

${ }^{29}$ Esta metodología se basa en McMillan y Rodrick (2011). Ha sido utilizada para el análisis de la formalización por Bertranou y Casanova (2014) en el caso argentino y por Díaz (2014) en el caso peruano.
Aquí, $\tau$ es la tasa de empleo formal, y se expresa como un promedio ponderado de las tasas de empleo formal en los sectores $\tau_{i}$, y la participación del sector $i$ en el empleo total, es decir, la estructura sectorial del empleo $\theta_{i}$ en cada período. La diferencia en la tasa de empleo formal en el período $t$ y el período $k$ puede escribirse de la siguiente forma:

$$
\Delta \tau_{i}=\sum \theta_{i, t-k} \Delta \tau_{i t}+\sum \tau_{i t} \Delta \theta_{i, t}
$$

Es decir, el cambio en la tasa de empleo formal se puede expresar como la suma de dos componentes. Con el primer componente - efecto tasa - se intenta medir el aporte del cambio en las tasas dentro de cada sector, manteniendo la estructura del empleo constante. Con el segundo componente - efecto composición - se intenta medir el cambio en la estructura sectorial del empleo, manteniendo la tasa de empleo formal constante. Los resultados de este ejercicio se muestran en el cuadro 4 , en el que se utiliza la definición de tasa de empleo formal para el período $2002-2012^{30}$. ${ }^{30}$ En este ejercicio se usó la tasa de empleo formal proveniente de las
encuestas de hogares en lugar de la tasa de empleo registrado, debido a
la disponibilidad de información sobre empleo desagregada por sectores.

Perú: descomposición del cambio en la tasa de empleo formal, 2002-2012

\begin{tabular}{|c|c|c|c|c|c|c|c|}
\hline & \multicolumn{2}{|c|}{ Tasa de empleo formal } & \multicolumn{2}{|c|}{$\begin{array}{c}\text { Participación } \\
\text { en el empleo total }\end{array}$} & \multicolumn{3}{|c|}{ Descomposición } \\
\hline & 2002 & 2012 & 2002 & 2012 & Efecto tasa & $\begin{array}{l}\text { Efecto } \\
\text { estructura }\end{array}$ & Suma \\
\hline \multicolumn{8}{|l|}{ Sector de actividad } \\
\hline Agropecuario y pesca & 5,4 & 7,4 & 33,3 & 24,6 & 0,5 & $-0,5$ & 0,0 \\
\hline Minería & 60,4 & 60,1 & 0,7 & 1,3 & $-0,0$ & 0,4 & 0,4 \\
\hline Manufactura & 22,6 & 32,4 & 10,1 & 10,8 & 1,1 & 0,2 & 1,2 \\
\hline Construcción & 12,8 & 23,9 & 3,7 & 5,9 & 0,7 & 0,3 & 0,9 \\
\hline Comercio & 13,1 & 18,8 & 17,4 & 17,9 & 1,0 & 0,1 & 1,1 \\
\hline Transporte y comunicaciones & 13,1 & 17,5 & 5,8 & 7,3 & 0,3 & 0,2 & 0,5 \\
\hline Restaurantes y alojamiento & 10,4 & 14,3 & 5,3 & 6,5 & 0,3 & 0,1 & 0,4 \\
\hline Otros servicios & 46,5 & 54,5 & 23,7 & 25,7 & 2,0 & 0,9 & 3,0 \\
\hline Total & 19,6 & 27,1 & 100,0 & 100,0 & 5,8 & 1,7 & 7,5 \\
\hline
\end{tabular}
(En porcentajes)

Fuente: Elaboración propia sobre la base de Instituto Nacional de Estadística e Informática (INEI), Encuesta Nacional de Hogares (ENAHO), varios años.

Nota: Clasificación de sectores según la Clasificación Industrial Internacional Uniforme de Todas las Actividades Económicas (CIIU). 
Se observa que el incremento de empleo formal de 6,5 puntos porcentuales, que se produjo en el Perú entre 2002 y 2012, se descompone en casi seis puntos porcentuales que procedieron del cambio en las tasas en el interior de los sectores y en 1,7 puntos porcentuales adicionales provenientes del cambio en la estructura sectorial del empleo. Es decir, este último cambio explica más del $20 \%$ del incremento en el empleo formal. Vale la pena destacar que el único sector que muestra un cambio nulo en el efecto composición es el sector Agropecuario y pesca debido a que es el único que redujo su participación en el empleo total. El sector Otros servicios (que incluye al gobierno) evidencia los efectos tasa y composición más elevados.

Por otra parte, es posible - y de hecho así lo confirman varios estudios recientes- que existan importantes recomposiciones intrasectoriales del empleo. Al respecto, Díaz (2014), mediante datos del período 2002-2011, realiza una descomposición similar y encuentra que más del $40 \%$ de la reducción en la informalidad se relaciona con el cambio en la estructura del empleo por tamaño de empresa. Infante y Chacaltana (2014) añaden que esto se debe a que las grandes y medianas empresas mostraron el mayor dinamismo en cuanto a producto, empleo y productividad en dicho período.

Hay que tener en cuenta que en este ejercicio solo se considera el cambio en la composición sectorial del empleo. En tal sentido, es necesario relacionar formalización y crecimiento sectorial de manera específica. Con este fin, en el presente trabajo se sigue la estrategia metodológica utilizada por Ravallion y Chen (2006) y Loayza y Raddatz (2006), quienes vincularon la composición del crecimiento con la evolución de la pobreza $^{31}$. Básicamente, aquí se propone una ecuación que vincula la formalización con la composición sectorial del crecimiento. Operativamente, esto implica estimar una ecuación que relaciona la variación de la tasa de empleo registrado a nivel regional con la variación de la producción sectorial a nivel de regiones. Dada la observación previa sobre el caso de Moquegua, se asume que la relación tiene efectos fijos regionales y, por lo tanto, adopta la siguiente forma:

$$
\Delta \tau_{j t}=\delta_{j}+\sum \delta_{i} \cdot s_{i j t} \cdot \Delta y_{i j t}+\varepsilon_{j t}
$$

\footnotetext{
${ }^{31}$ Ravallion y Chen (2006) analizan la relación entre composición del crecimiento y pobreza con datos de China. Loayza y Raddatz (2006) utilizan datos de países a nivel internacional y también relacionan pobreza y composición del crecimiento. Arias-Vásquez, Lee y Newhouse (2012) extienden este tipo de análisis a variables laborales aunque no analizan la formalidad.
}

Aquí, $\Delta \tau_{j t}$ es la variación de la tasa de empleo registrado en la región $j, \Delta y_{i j t}$ es la variación del valor agregado por trabajador en el sector $i$ en la región $j$, $S_{i j t}$ es la participación del sector $i$ en el valor agregado regional de la región $j$. Los coeficientes $\delta_{j}$ son efectos fijos regionales. Como se ha indicado en los estudios citados, la ventaja de esta especificación es que si todos los coeficientes $\delta_{i}$ son iguales, es posible sumar las variaciones de los valores agregados por sector ponderados por su participación en el valor agregado regional. En ese caso, la ecuación se transforma en una regresión simple entre la variación en la tasa de empleo registrado $\Delta \tau_{j t}$ y la variación del valor agregado regional $\Delta y_{j t}$. En ese sentido, si la hipótesis nula de que los coeficientes son iguales no puede ser rechazada, entonces solo importa el nivel del producto y no su composición. Por el contrario, si la hipótesis nula es rechazada, la composición del crecimiento sí resulta importante. En este artículo el foco está puesto en $\Delta \tau_{j t}$, porque precisamente se trata de estimar los efectos de la composición sectorial del crecimiento en una variable agregada a nivel territorial.

En el cuadro 5 se presentan dos estimaciones. La primera estimación — que se muestra en la primera columna de este cuadro - se realiza al utilizar la muestra panel con el método de máxima verosimilitud (ML). La segunda columna del cuadro contiene la misma estimación empleando datos combinados (pooled) con el método de mínimos cuadrados ordinarios (MCO), lo que ayuda a verificar si el panel no balanceado afecta a los resultados, que son prácticamente los mismos.

Los coeficientes que resultan significativos y positivos, con 99\% de confianza, son los de Agricultura y pesca, Comercio y Otros servicios. El coeficiente de Restaurantes y hoteles resulta significativo al $90 \%$. En todos los otros casos, los coeficientes no son significativos. En el caso de Agricultura y pesca, el coeficiente mayor que 1 significa que un cambio proporcional de un punto porcentual en el valor agregado por trabajador de este sector, implica un incremento de más de un punto porcentual en la tasa de empleo registrado a nivel regional. Lo mismo se aplica en el caso del sector Restaurantes y hoteles; $y$ en el de Comercio el coeficiente es aproximadamente igual a 1 .

En el caso del sector de Otros servicios (que incluye gobierno), el cambio es menos que proporcional. La prueba de igualdad de todos los coeficientes indica que la hipótesis nula de que todos los coeficientes sean iguales, se rechaza con el 99\% de confianza. Del mismo modo, se rechaza la hipótesis de que todos los coeficientes sean iguales a cero. Esto confirma la hipótesis de que el crecimiento de algunos sectores tiene mayor efecto 
CUADRO 5

Perú: resultados de la regresión entre variación de la tasa de empleo registrado y crecimiento sectorial

\begin{tabular}{|c|c|c|}
\hline & $\begin{array}{l}\text { Panel de datos } \\
\quad \text { (MV) }\end{array}$ & $\begin{array}{l}\text { Datos combinados } \\
\text { (MCO) }\end{array}$ \\
\hline \multicolumn{3}{|l|}{$\begin{array}{l}\text { Variación en la tasa de producto por trabajador sectorial } \\
\text { ponderada por participación en el valor agregado regional }\end{array}$} \\
\hline Agricultura y pesca & $\begin{array}{l}1,349 * * * \\
(0,244)\end{array}$ & $\begin{array}{l}1,414 * * * \\
(0,252)\end{array}$ \\
\hline Minería & $\begin{array}{l}-0,015 \\
(0,017)\end{array}$ & $\begin{array}{l}-0,020 \\
(0,018)\end{array}$ \\
\hline Manufactura & $\begin{array}{c}0,068 \\
(0,153)\end{array}$ & $\begin{array}{c}0,113 \\
(0,167)\end{array}$ \\
\hline Construcción & $\begin{array}{l}-0,011 \\
(0,152)\end{array}$ & $\begin{array}{l}-0,008 \\
(0,164)\end{array}$ \\
\hline Comercio & $\begin{array}{l}1,038 * * * \\
(0,295)\end{array}$ & $\begin{array}{l}0,990 * * \\
(0,313)\end{array}$ \\
\hline Transportes y comunicaciones & $\begin{array}{c}0,541 \\
(0,298)\end{array}$ & $\begin{array}{c}0,557 \\
(0,327)\end{array}$ \\
\hline Restaurantes y hoteles & $\begin{array}{c}1,410^{*} \\
(0,552)\end{array}$ & $\begin{array}{c}1,406^{*} \\
(0,611)\end{array}$ \\
\hline Otros servicios & $\begin{array}{l}0,681 * * * \\
(0,197)\end{array}$ & $\begin{array}{l}0,640 * * \\
(0,210)\end{array}$ \\
\hline Test 1: igualdad de coeficientes & 0,00 & 0,00 \\
\hline Test 2: coeficientes iguales a 0 & 0,00 & 0,00 \\
\hline Test 3: igualdad de coeficientes de sectores intensivos en empleo & 0,14 & 0,11 \\
\hline Test 4: igualdad de coeficientes de sectores no intensivos en empleo & 0,25 & 0,24 \\
\hline $\mathrm{R}^{2}$ Ajustado & & 0,28 \\
\hline Rho & 0,17 & \\
\hline Número de observaciones & 175 & 175 \\
\hline
\end{tabular}

Fuente: Elaboración propia.

Nota: $(*)=$ significancia al $10 \%,(* *)=$ significancia al $5 \%$ y $(* * *)=$ significancia al $1 \%$.

Desviación estándar entre paréntesis.

Sectores intensivos en empleo: Agricultura y pesca, Comercio, Restaurantes y hoteles, y Otros servicios.

MV: Máxima verosimilitud; MCO: Mínimos cuadrados ordinarios.

en el aumento de la tasa de empleo registrado que el de otros y, por lo tanto, que la composición del crecimiento importa. Se realiza un ejercicio adicional de igualdad de coeficientes por subgrupos y no se puede rechazar la hipótesis de que los coeficientes de los sectores con coeficiente significativo sean iguales entre sí. Similar resultado ocurre cuando se agrupa a los sectores con coeficiente no significativo.

¿Por qué algunos sectores repercuten más en la formalidad que otros ${ }^{32}$ ? En el panel A del gráfico 5 se aprecia que los sectores que obtienen coeficientes significativos (Agricultura y pesca, Comercio, Restaurantes y hoteles y Otros servicios) son, en general, muy intensivos en empleo, es decir, que su número de trabajadores

\footnotetext{
${ }^{32}$ No se cuenta con información regional de producción por tamaño de la empresa.
}

como proporción del empleo regional es alto. En el caso de Agricultura y pesca, su participación en el empleo regional varía entre un $5 \%$ y el $80 \%$ entre regiones. $\mathrm{Al}$ mismo tiempo, estos sectores muestran menores niveles de valor agregado por trabajador, que no alcanza a los 20 mil nuevos soles anuales en ninguna región (panel B del gráfico 5). Además, son sectores donde existe baja formalidad. En ese sentido, es probable que con una baja tasa de empleo registrado inicial, similares cambios en la producción impliquen cambios mayores tanto en las tasas como en la cantidad de trabajadores formalizados ${ }^{33}$.

\footnotetext{
${ }^{33}$ Además, existe evidencia de que el crecimiento de la agricultura se ha concentrado en algunas regiones del país, donde se ha producido una recomposición del empleo de sectores de baja productividad a sectores más productivos. Algunos han asociado estos cambios a la Ley de Promoción del Sector Agrario (Ley N 27360 del año 2001) cuyo análisis excede los límites de este artículo. Véase Infante y Chacaltana (2014).
} 
GRÁFICO 5

Perú: distribución regional de intensidad del empleo y del valor agregado por trabajador según sectores, 2002-2012

A. Intensidad del empleo (2002-2012)

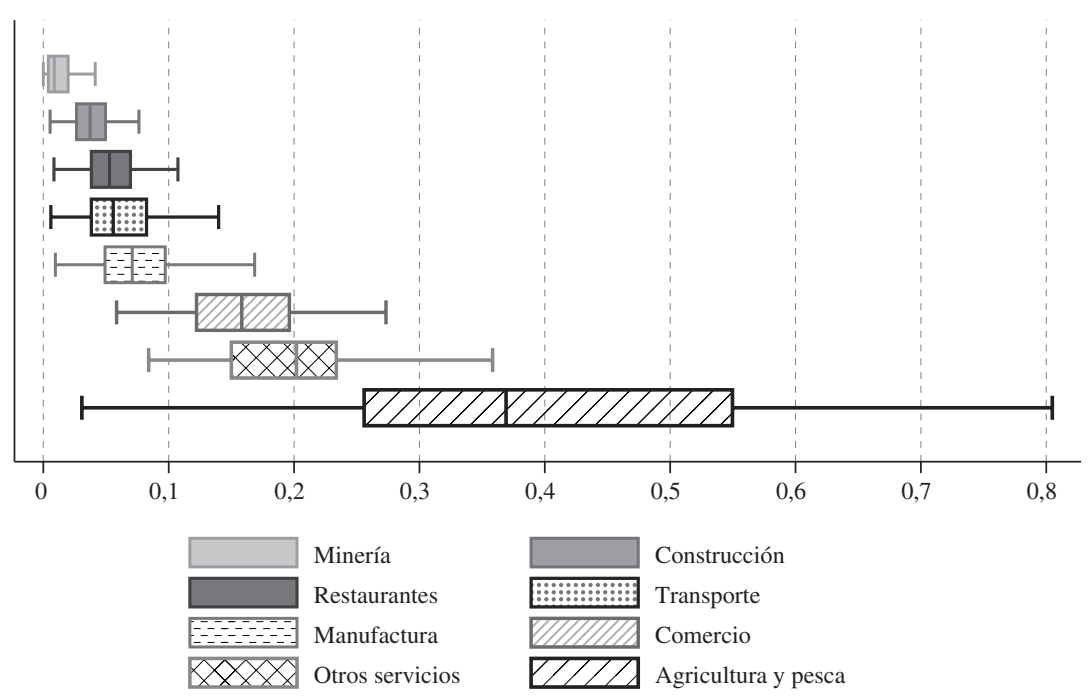

B. Valor agregado por trabajador, 2002-2012

(En nuevos soles)

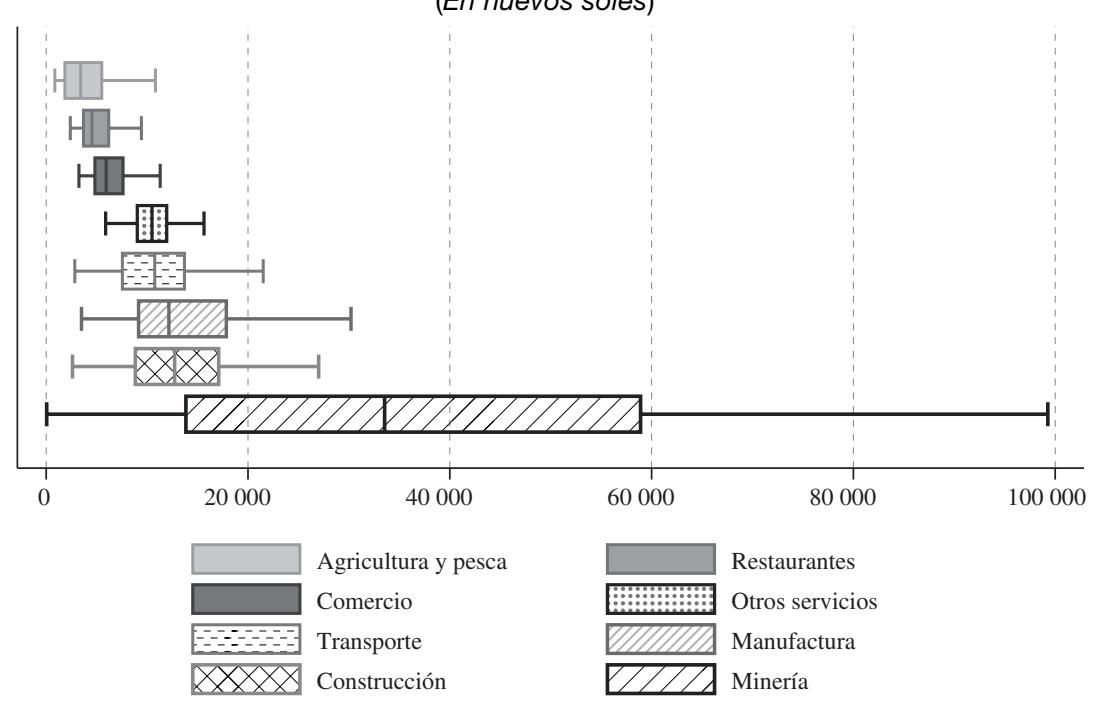

Fuente: Elaboración propia sobre la base de Instituto Nacional de Estadística e Informática (INEI), Encuesta Nacional de Hogares (ENAHO), varios años.

Nota: Participación del empleo en sector "i" de la región "j”" sobre el empleo total en la región "j”. El producto por trabajador de cada región se mide en nuevos soles de 1994. 


\section{Formalización 2002-2012: factores explicativos}

En esta subsección se analizan de manera combinada diversos elementos que pueden influir en el proceso de formalización en el Perú, según lo observado entre 2002 y 2012. Cada factor podría tener una relación individual significativa con la formalidad, pero es importante verificar si dicha significancia se mantiene controlando variables o hipótesis competidoras. En ese sentido, resulta importante analizar de manera conjunta factores económicos — magnitud y composición-, como también variables asociadas a cambios normativos o institucionales que han concurrido en este período.

De acuerdo con lo analizado en las secciones previas, se evalúan cuatro posibles factores destacados por la literatura, así como por la discusión académica y política reciente:

i) El crecimiento económico. En el período de análisis, el PIB creció a una tasa de $6 \%$ anual, lo que implicó un crecimiento de la economía del $70 \%$ en términos reales. Asimismo, el valor agregado regional por trabajador también aumentó en el período de análisis.

ii) El cambio en la estructura productiva, en vista del resultado de que la composición sectorial del crecimiento importa. En particular, interesa evaluar de manera comparativa el papel que ha podido jugar el crecimiento de la participación en la producción de los sectores más intensivos en empleo (Agricultura y pesca, Comercio, Restaurantes y hoteles, y Otros servicios), los que fueron identificados anteriormente con aporte significativo. iii) Cambios normativos. Se produjo una reforma laboral importante que, según sus autores, se orientó específicamente a la reducción de costos laborales creando un régimen especial para las MYPE. Esto ocurrió en 2003 y luego se amplió en 2008 (aplicación a partir del año 2009). A fin de evaluar el efecto de estos cambios normativos en la formalización, en el marco de la base de datos aquí utilizada, se procedió a calcular el costo laboral promedio ponderado en cada región. Para ello, se utiliza la estructura de empleo por tamaño de empresa a fin de ponderar el costo laboral correspondiente (véase el gráfico 3 ).

iv) Cambios en la capacidad del Estado para hacer cumplir sus normas. Como se ha mencionado, aquí también se produjeron cambios importantes y por eso mismo resulta difícil conseguir estadísticas comparables en el tiempo. En tal sentido, se utiliza el número de órdenes inspectivas concluidas por el MTPE por cada mil trabajadores como proxy de la probabilidad de detección ${ }^{34}$. La cobertura de las inspecciones es más bien baja en el Perú y se concentra sobre todo en las empresas formales y se aplica a trabajadores asalariados. Se espera que un incremento en la probabilidad de detección mejore la tasa de empleo registrado.

En el gráfico 6 se muestran correlaciones parciales simples de estas variables en variaciones. Se observa

34 Los datos de inspecciones fueron obtenidos de los Anuarios Estadísticos del Ministerio de Trabajo y Promoción del Empleo (MTPE).
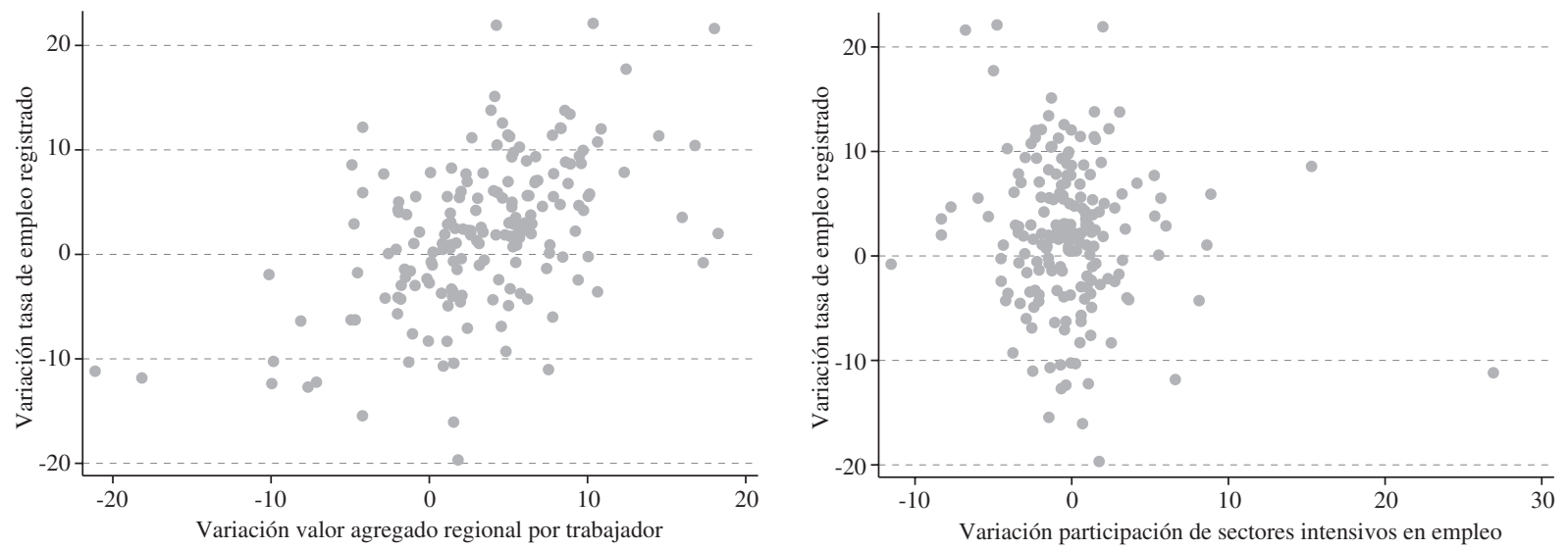
Gráfico 6 (conclusión)
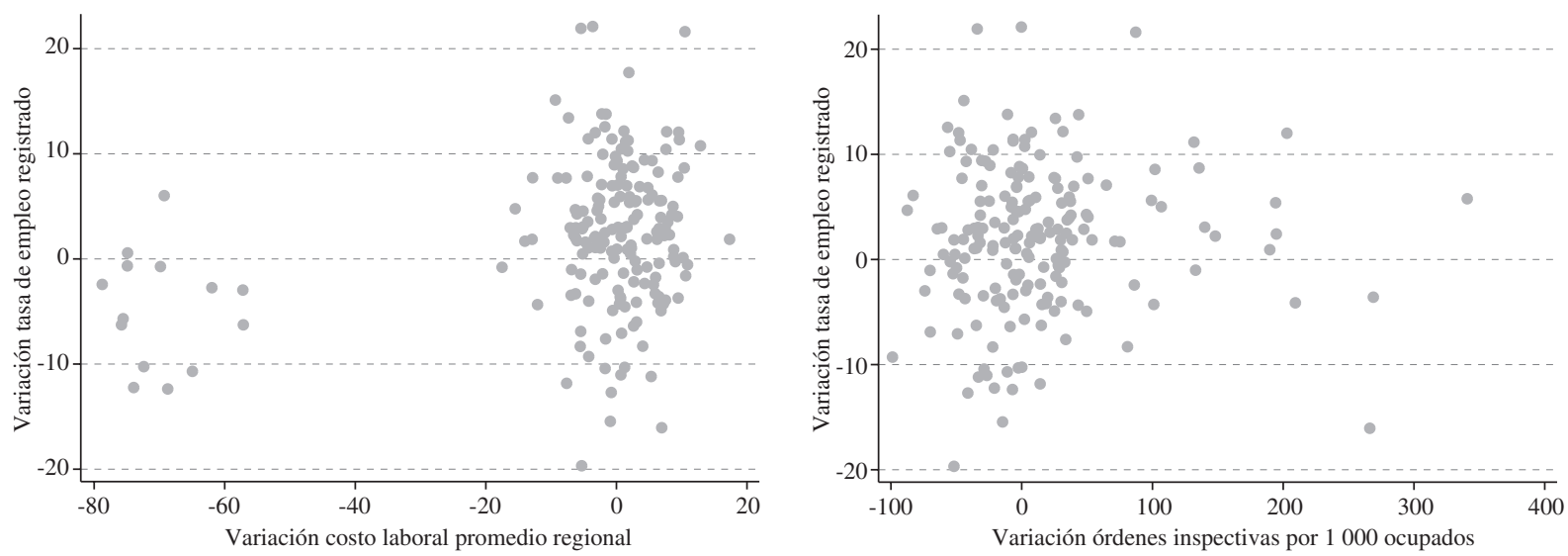

Fuente: Elaboración propia sobre la base de información del Instituto Nacional de Estadística e Informática (INEI), el Ministerio de Trabajo y Promoción del Empleo (MTPE), la Encuesta Nacional de Hogares (ENAHO) y la Ley $\mathrm{N}^{\circ} 30288$.

Nota: Sectores intensivos en empleo: Agricultura y pesca, Comercio, Restaurantes y hoteles, y Otros servicios.

una correlación mayor entre formalización y variables económicas que entre formalización y las variables de reforma (variación del costo laboral promedio regional) o inspección (variación de las órdenes inspectivas por cada 1.000 ocupados). En especial, la correlación entre formalización y el crecimiento regional (variación del valor agregado regional por trabajador) es alta, lo que evidencia que el quantum de crecimiento tiene una elevada importancia. La correlación entre formalización y la variación de la participación de los sectores intensivos en empleo también muestra una relación positiva, de manera consistente con el hallazgo previo de que el crecimiento sectorial es relevante.

Luego se procedió a analizar de manera conjunta todos estos factores por medio de un análisis de regresión múltiple ${ }^{35}$.

$$
\Delta \tau_{j t}=\beta_{j}+\beta_{1} \Delta y_{j t}+\beta_{2} \Delta s_{j t}^{\text {alta }}+\beta_{3} \Delta r_{j t}+\beta_{4} \Delta f_{j t}+\xi_{j t}
$$

En este caso, $\beta_{j}$ son los efectos fijos regionales, $\Delta y_{j t}$ es el crecimiento del valor agregado regional por trabajador, $s_{j t}^{\text {alta }}$ es el cambio en la participación de los sectores de alta intensidad de uso de mano de obra en el

$35 \mathrm{El}$ análisis de regresión múltiple aquí presentado solo tiene por finalidad analizar de manera controlada el efecto de diversas variables en el empleo registrado. No pretende evaluar el impacto individual de cada una de ellas. Existen estudios en que se han intentado evaluar algunos de estos factores de manera separada. Para evaluar de manera conjunta todos estos factores se requeriría un análisis de multitratamientos, lo que excede el límite de este artículo. valor agregado regional, $\Delta r_{j t}$ es la variable que aproxima la incorporación de la Ley MYPE y $\Delta f_{j t}$ es el cambio en la tasa de órdenes inspectivas por cada 1.000 trabajadores. Los resultados de este ejercicio se muestran en el cuadro 6, donde se presentan diversas estimaciones que van incorporando progresivamente las diferentes variables.

En el panel (a) del cuadro 6 se utiliza una regresión en variaciones. En primer lugar, se relaciona la variación de la tasa de empleo registrado con el crecimiento del valor agregado regional por trabajador. El coeficiente resulta significativo al $1 \%$ (modelo 1 del cuadro 6). Luego se añade a esta regresión una variable que representa el crecimiento de la participación de los sectores intensivos en empleo en el valor agregado regional. Su coeficiente resulta también significativo al $5 \%$ y se mantiene la significancia del valor agregado regional por trabajador (modelo 2). En tercer lugar, se agrega la variable que aproxima la incorporación de la Ley MYPE (la variación del costo laboral promedio ponderado a nivel regional) y su efecto resulta no significativo aun cuando la significancia de las variables previas se mantiene (modelo 3). Finalmente, se añade la variable relacionada con los cambios en la inspección y su incorporación resulta no significativa, no alterando los resultados previos (modelo 4). De manera interesante, el coeficiente de ajuste $\mathrm{R}^{2}$ ajustado es de 0,31 cuando solo se toma en cuenta el valor agregado regional por trabajador (modelo 1) y se incrementa a 0,35 cuando se añade el cambio en la composición del crecimiento (modelo 2).

De manera alternativa, en el panel (b) del cuadro 6 se utilizan variables dummy como proxy de las variables 
Resultados de regresión múltiple, 2002-2012

a. Variables de crecimiento económico y cambios institucionales (en variaciones)

\begin{tabular}{|c|c|c|c|c|}
\hline Dependiente: variación de la tasa de empleo registrado & Modelo 1 & Modelo 2 & Modelo 3 & Modelo 4 \\
\hline Variación del valor agregado regional por trabajador & $\begin{array}{l}0,633 * * * \\
(0,068)\end{array}$ & $\begin{array}{l}0,781 * * * \\
(0,079)\end{array}$ & $\begin{array}{l}0,759 * * * \\
(0,079)\end{array}$ & $\begin{array}{l}0,747 * * * \\
(0,080)\end{array}$ \\
\hline Variación de los costos laborales regionales & & & $\begin{array}{c}0,038 \\
(0,022)\end{array}$ & $\begin{array}{c}0,038 \\
(0,022)\end{array}$ \\
\hline $\begin{array}{l}\text { Variación de la tasa de órdenes inspectivas cerradas por cada } 1000 \\
\text { ocupados por región }\end{array}$ & & & & $\begin{array}{c}0,001 \\
(0,001)\end{array}$ \\
\hline Prueba F & 86,3 & 51,9 & 36,0 & 27,3 \\
\hline Prob > F (valor $p)$ & 0,00 & 0,00 & 0,00 & 0,00 \\
\hline $\mathrm{R}^{2}$ ajustado & 0,314 & 0,354 & 0,361 & 0,361 \\
\hline $\mathrm{N}^{\mathrm{o}}$ de observaciones & 186 & 186 & 186 & 186 \\
\hline
\end{tabular}

b. Variables de crecimiento económico y cambios institucionales (variables dummy)

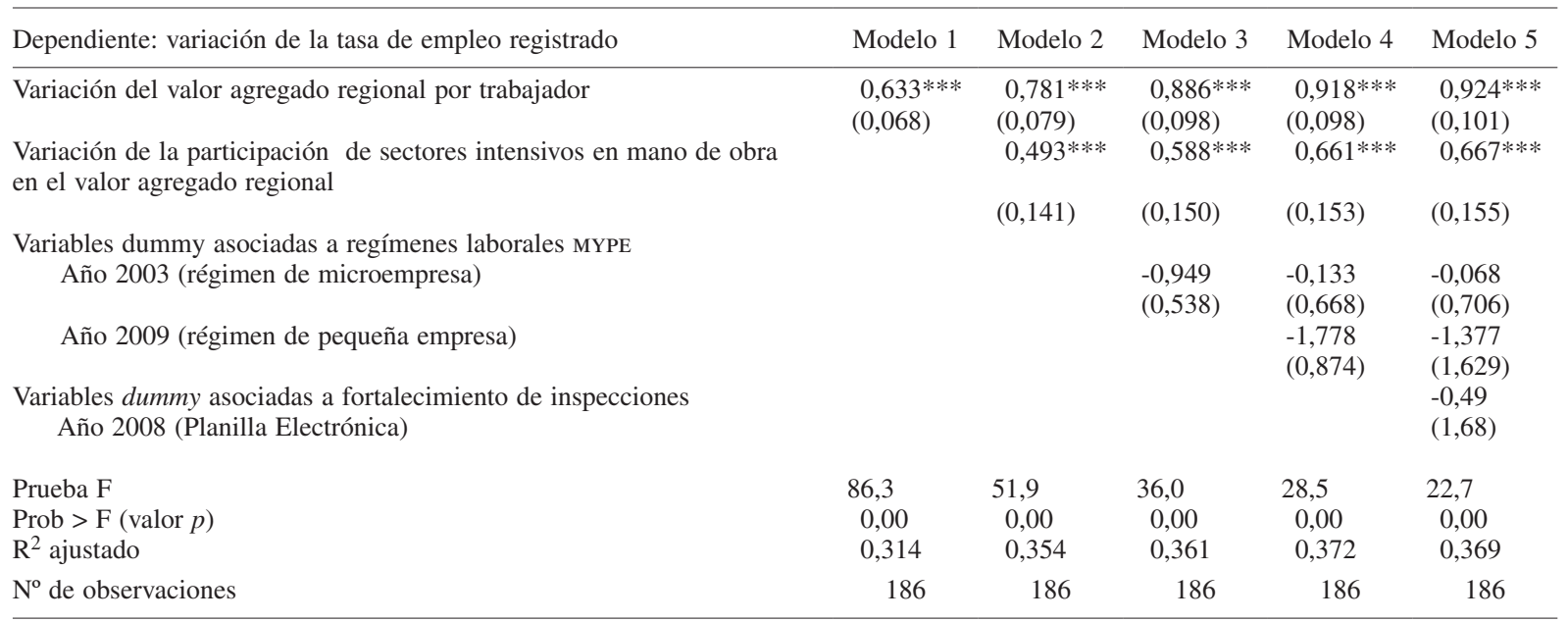

Fuente: Elaboración propia sobre la base de información del Instituto Nacional de Estadística e Informática (INEI), el Ministerio de Trabajo y Promoción del Empleo (MTPE), la Encuesta Nacional de Hogares (ENAHO) y la Ley N 30288.

Nota: $(*)=$ significancia al $10 \%,(* *)=$ significancia al $5 \%$ y $(* * *)=$ significancia al $1 \%$.

Desviación estándar entre paréntesis. Sectores intensivos en empleo: Agricultura y pesca, Comercio, Restaurantes y hoteles, y Otros servicios.

institucionales. En este caso, se emplea una primera dummy para el año 2003, año en que se generó el régimen laboral para las microempresas (modelo 3) y una segunda para el año 2009, cuando se inició la aplicación de la ampliación de dicha ley a empresas con hasta 100 trabajadores (modelo 4). Por otra parte, a fin de aproximar el efecto de la "Planilla Electrónica" ${ }^{36}$ se

36 La planilla electrónica es un procedimiento electrónico mediante el cual los empleadores que cuentan con tres trabajadores o más deben reportar a la Superintendencia Nacional de Administración Tributaria (SUNAT), con una frecuencia mensual, la información correspondiente de sus trabajadores, pensionistas, prestadores de servicios, personal en modalidades formativas, personal de terceros y derechohabientes. generó también una dummy para el año 2008, año de su aplicación obligatoria (modelo 5) ${ }^{37}$. El análisis de estas variables, controlando mediante el crecimiento del valor agregado regional por trabajador y el crecimiento

Anteriormente, el reporte se realizaba directamente al Ministerio de Trabajo. Este cambio administrativo ha incrementado la capacidad de este Ministerio para supervisar y fiscalizar el cumplimiento de las obligaciones laborales, puesto que aprovecha la capacidad instalada y de detección de la Sunat (OIT, 2014b).

37 Dado que son cambios permanentes, se utilizaron dummies con el valor 1 para el año correspondiente y para los siguientes años. Las dummies son nacionales porque el régimen no varía por regiones subnacionales. 
sectorial, ratifica coeficientes no significativos para estas variables.

Estos resultados implican que el incremento del valor agregado por trabajador en las regiones ha resultado un elemento determinante en el proceso de aumento de la tasa de empleo registrado en el Perú. El crecimiento de ciertos sectores, como el de aquellos más intensivos en empleo, también agrega poder explicativo a este proceso. Las variables asociadas a la reforma laboral no

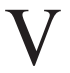

\section{Conclusiones}

Perú registró altas tasas de crecimiento en la década de 2000 y principios del decenio de 2010. Este período de crecimiento económico permitió una reducción de las tasas de desempleo que, a nivel nacional, llegaron a mínimos históricos de menos del $4 \%$ en 2013. También se ha observado una significativa disminución de la tasa de pobreza a menos de la mitad con respecto a inicios de la década de 2000, lo que ciertamente indica un mejoramiento en los ingresos, aunque también destaca el papel de la política social de tipo redistributivo y su vinculación con la mayor disponibilidad fiscal. A su vez, el porcentaje de empleo formal pasó del 20,1\% al $26,3 \%$ entre 2007 y 2012. Este es un hecho notable a pesar de que la tasa de informalidad aún sea muy alta.

En este artículo se analizó este proceso de formalización y se trató de identificar los factores que podrían explicarlo. Gran parte de la discusión previa se ha concentrado en algunas relaciones específicas, sobre todo la relación entre informalidad y reforma laboral. Aquí el objetivo consistió en identificar el aporte de cada elemento en el marco de un enfoque integrado, donde se presume que diversas políticas pueden tener algún poder explicativo. El caso peruano es un caso interesante para el propósito señalado, porque en el período de análisis concurrieron diversos factores que en teoría podrían explicar este proceso, por ejemplo, el crecimiento económico o la reforma laboral —que implicó la creación de un régimen especial que redujo los costos del trabajo para la mayor parte del mercado laboral-, así como mejoras en el sistema de inspección. Todos estos elementos han sido destacados por diversas teorías como explicativas de la informalidad y, por lo tanto, de la formalidad.

El análisis se realizó en dos etapas. Primero, sobre la base de un modelo desarrollado originalmente para resultan significativas, en contraste con la magnitud de los cambios que esta involucró. Similar es el caso del fortalecimiento de la inspección, que continúa siendo débil a pesar de los cambios operados ${ }^{38}$.

38 Cabe mencionar que en 2013 se creó la Superintendencia de Inspecciones Laborales (SUNAFIL) con la finalidad de fortalecer el servicio inspectivo. medir los efectos del crecimiento sectorial en la pobreza, se estimaron los efectos del crecimiento sectorial en la formalización. Los resultados demuestran que los efectos sectoriales son diferenciados, lo que confirma la hipótesis de que la composición del crecimiento importa para la formalización. En particular, el crecimiento económico de los sectores más intensivos en empleo (Agricultura, Comercio, Otros servicios y, en cierta medida, Restaurantes y hoteles) explica el proceso de formalización observado. Luego, considerando que la formalización es un proceso con múltiples causas, se analizaron comparativamente aquellos factores que estarían detrás del proceso de crecimiento de la tasa de empleo registrado ocurrido entre 2002 y 2012. Los resultados indican que un elemento central ha sido el crecimiento del valor agregado regional por trabajador. También tiene un efecto significativo que haya crecido la participación del valor agregado por trabajador de los sectores más intensivos en empleo y que, al mismo tiempo, tienen menor productividad, lo que indica que su valor agregado por trabajador ha crecido más rápido que el valor agregado regional por trabajador. Las variables asociadas a la reforma laboral o a los cambios en la inspección no han tenido efectos significativos.

Estos resultados son consistentes con el hecho de que, en el Perú, al menos dos de cada tres trabajadores con empleo informal laboran en unidades económicas informales, que no están registradas como negocios ni en los sistemas tributarios, y que las unidades económicas del sector informal tienen niveles de productividad equivalentes a un octavo de las del sector formal. En estas circunstancias, es explicable que solo las variables vinculadas al crecimiento y, sobre todo, al crecimiento de los sectores de menor productividad, tengan coeficientes significativos. Esto implica que la formalización laboral 
requiere previamente un proceso de formalización de las unidades económicas donde se genera el empleo informal. Por consiguiente, probablemente el énfasis en la reducción de costos del trabajo para las MYPE deba ser reemplazado por un mayor énfasis en potenciar los beneficios de la formalidad, tales como acceso a mercados más amplios, financiamiento, servicios de desarrollo empresarial y seguridad, entre otros.

\section{Bibliografía}

Acemoglu, D. (2001), "Good jobs versus bad jobs", Journal of Labor Economics, vol. 19, $\mathrm{N}^{\circ}$ 1, Chicago, University of Chicago Press.

Arias-Vásquez, F.J., J.N. Lee y D. Newhouse (2012), The Role of Sectoral Growth Patterns in Labor Market Developments, Washington, D.C., Banco Mundial.

Berg, J. (2010), "Laws or luck? Understanding rising formality in Brazil in the 2000s", MPRA Paper, $\mathrm{N}^{\circ}$ 43608, Munich, University Library of Munich.

Bertranou, F. y L. Casanova (2014), Informalidad laboral en Argentina, Buenos Aires, Organización Internacional del Trabajo (OIT).

Bhagwati, J. y A. Panagriva (2013), "Why growth matters: how economic growth in India reduced poverty and lessons for other developing countries", PublicAffairs, Nueva York.

Chacaltana, J. (2008), "Una evaluación del régimen laboral especial para la microempresa en Perú, al cuarto año de vigencia", Lima, Organización Internacional del Trabajo (OIT), inédito.

(2007), Desafiando al desierto: realidad y perspectivas del empleo en Ica, Lima, Centro de Estudios para el Desarrollo y la Participación (CEDEP).

(2001), "Reforma en la contratación y el despido en el Perú de los noventa", Revista Economía, vol. 24, N 48, Lima, Pontificia Universidad Católica del Perú.

Chang, H.-J. (2007), Bad Samaritans. Rich Nations, Poor Policies, and the Threat of the Developing World, Londres, Random House.

Chong, A., J. Galdo y J. Saavedra (2007), Informality and Productivity in the Labor Market: Peru 1986-2001, Washington, D.C., Banco Interamericano de Desarrollo (BID).

De Janvry, A. y E. Sadoulet (2010), "Agricultural growth and poverty reduction: additional evidence", World Bank Research Observer, vol. 25, $\mathrm{N}^{\circ} 1$, Oxford University Press.

De Soto, H. y otros (1986), El otro sendero: la revolución informal, Lima, El Barranco.

Díaz, J.J. (2014), "Formalización empresarial y laboral", Hacia un desarrollo inclusivo. El caso de Perú, R. Infante y J. Chacaltana (eds.), Santiago, Comisión Económica para América Latina y el Caribe (CEPAL)/Organización Internacional del Trabajo (OIT).

Doeringer, P.B. y M.J. Piore (1971), International Labor Markets and Manpower Analysis, Heath Lexington Books.

El Peruano (2014), "Ley $\mathrm{N}^{\circ} 30288$ ", Lima, 16 de diciembre.

Fields, G. (1990), "Labour market modeling and the urban informal sector: theory and evidence", The Informal Sector Revisited, D. Turnham, B. Salomé y A. Schwarz (eds.), París, Organización para la Cooperación y el Desarrollo Económicos (OCDE).

Hart, K. (1972), Employment, Income and Inequality: A Strategy for Increasing Productive Employment in Kenya, Ginebra, Organización Internacional del Trabajo (OIT).

INEI (Instituto Nacional de Estadística e Informática) (2014), Producción y empleo informal en el Perú. Cuenta satélite de la economía informal 2007-2012, Lima.

(2013), Compendio estadístico del Perú, 2013, Lima

Infante, R. y O. Sunkel (2012), "La heterogeneidad de la estructura productiva latinoamericana", Santiago, Comisión Económica para América Latina y el Caribe (CEPAL).

Infante, R. y J. Chacaltana (2014), Hacia un desarrollo inclusivo. El caso de Perú, Santiago, Comisión Económica para América
Latina y el Caribe (CEPAL)/Organización Internacional del Trabajo (OIT).

Infante, R., J. Chacaltana y M. Higa (2014), “Aspectos estructurales del desempeño macroeconómico del Perú. Situación actual, perspectivas y políticas", Hacia un desarrollo inclusivo. El caso de Perú, R. Infante y J. Chacaltana (eds.), Santiago, Comisión Económica para América Latina y el Caribe (CEPAL)/ Organización Internacional del Trabajo (OIT).

Jaramillo, M. (2013), Employment Growth and Segmentation in Peru, 2001-2011. Country Case Study on Labour Market Segmentation, Ginebra, Organización Internacional del Trabajo (OIT).

Kaldor, N. (1961), Capital Accumulation and Economic Growth, París, Organización de las Naciones Unidas para la Educación, la Ciencia y la Cultura (UNESCO).

Kanbur, R. (2009), "Conceptualizing informality: regulation and enforcement", Indian Journal of Labour Economics, vol. 52, $\mathrm{N}^{\circ}$ 1, Cambridge, Massachusetts, Mujeres en Empleo Informal: Globalizando y Organizando (WIEGO).

León, J. y R. Cermeño (1990), Las interrelaciones entre los sectores formal e informal en Lima Metropolitana: el caso de la industria, Lima, Pontificia Universidad Católica del Perú.

Levy, S. (2008), Good Intentions, Bad Outcomes. Social Policy, Informality, and Economic Growth in Mexico, Washington, D.C., Brooking Institution Press.

Lewis, A. (1954), "Economic development with unlimited supplies of labour", The Manchester School, vol. 22, N 2 , Wiley.

Loayza, N. (2013), Causas y consecuencias de la informalidad en el Perú, Lima, Banco Central de Reserva del Perú.

Loayza, N. y C. Raddatz (2006), "The composition of growth matters for poverty alleviation", Policy Research Working Papers, Washington, D.C., Banco Mundial.

Machado, R. (2012), "La economía informal en el Perú: magnitud y determinantes (1980-2011)", Apuntes del CIUP, vol. 41, $\mathrm{N}^{\circ} 74$, Lima, Universidad del Pacífico.

Maloney, W.F. (1999), "Does informality imply segmentation in urban labor markets? Evidence from sectoral transitions in Mexico", The World Bank Economic Review, vol. 13, ํㅜㄹ, Oxford University Press.

McMillan, M.S. y D. Rodrik (2011), "Globalization, structural change and productivity growth", NBER Working Paper, $\mathrm{N}^{\circ} 17143$ Cambridge, Massachusetts, National Bureau of Economic Research (NBER).

Mef (Ministerio de Economía y Finanzas) (2011), Marco macroeconómico multianual 2012-2014, Lima.

OIT (Organización Internacional del Trabajo) (2015), Recomendación sobre la transición de la economía informal a la economía formal, Ginebra, Conferencia Internacional del Trabajo.

(2014), Panorama Laboral 2014. América Latina y el Caribe, Lima.

(2014b), Evolución del empleo informal en Perú: 20042012. Serie de Notas ForLac sobre Formalización, Lima. (2013), La medición de la informalidad: manual estadístico sobre el sector informal y el empleo informal, Ginebra.

(2002), Informe IV. El trabajo decente y la economía informal, 90a Conferencia Internacional del Trabajo, Ginebra.

Perry, G. y otros (2007), Informality: Exit and Exclusion, Washington, D.C., Banco Mundial. 
Portes, A., M. Castells y L. Benton (1989), The Informal Economy. Studies in Advanced and Less Developed Countries, Baltimore, Johns Hopkins University Press.

Ravallion, M. y S. Chen (2006), China's (Uneven) Progress against Poverty, Washington, D.C., Banco Mundial.

Ray, D. (2010), "Uneven growth: a framework for research in development economies", Journal of Economic Perspectives, vol. 24, $\mathrm{N}^{\circ}$ 3, Nashville, Tennessee, American Economic Association.

Solimano, A. (1996), Road Maps to Prosperity. Essays on Growth and Development, Ann Arbor, The University of Michigan Press.

Távara, J., E. González de Olarte y J.M. del Pozo (2014), "Heterogeneidad estructural y articulación productiva en el Perú: evolución y estrategias", Hacia un desarrollo inclusivo. El caso de Perú, R. Infante y J. Chacaltana (eds.), Santiago, Comisión Económica para América Latina y el Caribe (CEPAL)/ Organización Internacional del Trabajo (OIT).
Tello, M. (2012), “Labor productivity in Peru: 1997-2007”, Journal of CENTRUM Cathedra, vol. 5, $\mathrm{N}^{\circ} 1$.

Tokman, V.E. (1978), "An exploration into the nature of informalformal sector relationships", World Development, vol. 6, $\mathrm{N}^{\circ}$ 9-10, Amsterdam, Elsevier.

Verdera, F. (2014), "Do limits exist to informality growth in South America? A preliminary exploration", The Informal Economy in Developing Countries, J-P. Cling y otros (eds.), Nueva York, Routledge.

WIEGO (Mujeres en Empleo Informal: Globalizando y Organizando) (2012), The Informal Economy: Definitions, Theories and Policies, Cambridge, Massachusetts.

Yamada, G. (1996), "Urban informal employment and self employment in development countries: theory and evidence", Economic Development and Cultural Change, vol. 44, $\mathrm{N}^{\circ} 2$, Chicago, The University of Chicago Press. 